Denise Frediani Barbeiro

\title{
Participação da Célula B-1 na resposta inflamatória ao Lipopolissacáride
}

Tese apresentada à Faculdade de Medicina da Universidade de São Paulo, para obtenção do título de Doutor em Ciências

Área de concentração: Emergências Clínicas Orientador: Prof. Dr. Francisco Garcia Soriano

\section{São Paulo}


Dados Internacionais de Catalogação na Publicação (CIP)

Preparada pela Biblioteca da

Faculdade de Medicina da Universidade de São Paulo

Creprodução autorizada pelo autor

Barbeiro, Denise Frediani

Participação da célula B-1 na resposta inflamatória ao lipopolissacáride / Denise Frediani Barbeiro. -- São Paulo, 2009.

Tese(doutorado)--Faculdade de Medicina da Universidade de São Paulo.

Departamento de Clínica Médica.

Área de concentração: Emergências Clínicas.

Orientador: Francisco Garcia Soriano.

Descritores: 1.Linfócitos B/imunologia 2.Macrófagos

3.Lipopolissacarídeos/imunologia 4.Endotoxemia 5.Inflamação

USP/FM/SBD-371/09 


\section{Agradecimentos}

Ao meu orientador Francisco Garcia Soriano pelos ensinamentos, disponibilidade, dedicação e amizade que foram essenciais para a realização desta tese;

Ao prof. Dr. Irineu Tadeu Velasco e ao Prof. Dr. Heraldo Possolo de Souza pela oportunidade de realizar esta tese no LIM 51;

Aos amigos Susi, Suely, Geraldo, Kelli, Fátima, Solange, Nancy e Thaís pela alegria, amizade e companheirismo que ajudaram direta ou indiretamente para a realização desta tese;

À Dra. Cláudia, Vicência e Edson pelo espaço cedido no biotério do LIM -7 e dedicação na manutenção dos animais;

Ao professor Mário Mariano, Ana Flávia Popi e Dr. Joel Faintuch pela oportunidade de realizar as análises de citometria de fluxo no laboratório de imunologia da UNIFESP e pelas valiosas orientações para a realização desta tese;

Ao meu marido Hermes, companheiro maravilhoso, por acreditar em meu potencial, pela presença em todos os momentos me ensinando, estimulando e ajudando na realização desta tese.

A minha família pelo suporte emocional e por estarem sempre presentes em todas as conquistas pessoais e profissionais. 


\section{Sumário}

Lista de abreviaturas e siglas

Lista de Figuras

Resumo

Summary

1. Introdução 1

1.1. Síndrome da Resposta Inflamatória Sistêmica (SIRS) e Sepse 1

1.2. Detecção do invasor e sinalização intracelular ___ 3

1.3. Sinalização intercelular __ 4

1.3.1. Fator de Necrose Tumoral alfa (TNF- $\alpha) \_5$

1.3.2. Interleucina-6 (IL-6)__ 5

1.3.3. Interleucina-10 (IL-10)__ 6

1.3.4. Óxido Nítrico ___ 6

1.4. Células participantes da resposta inflamatória ___ 7

1.5.- Célula B-1__ 8

1.6. Características clínicas da imunodeficiência de linfócitos B ___ 9

2. Objetivos __ 10

3. Materiais e Métodos ___ 11

3.1. Cultura de células __ 12

3.1.1 Células peritoneais aderentes___ 12

3.1.2. Cultura de macrófagos ___ 12

3.1.3. Cultura de células B-1__ 13

3.1.4. Coculturas de macrófagos e células B-1__ 14

3.2. Estímulo das células com LPS in vitro ___ 14

3.3. Estímulo de macrófagos (RAW 264.7) com IL-10 recombinante (rIL-10) ___ 14

3.4. Modelo de Endotoxemia ___ 18

3.5. Mediadores inflamatórios no modelo de endotoxemia ___ 18

3.6. Inoculação de Célula B-1 (Balb/c) em peritônio de Balb/Xid ___ 19

3.7. Curva de Sobrevida __ 20

3.8. Detecção de células B-1: Citometria de Fluxo ___ 20

3.9. Detecção de IgM em cultura de célula B-1. ___ 21 
3.10. Preparo das amostras de pulmão e intestino para dosagem de TNF- $\alpha$, IL-6 e IL-10 por ELISA

3.11. Quantificação TNF- $\alpha$, IL-6 e IL-10 por ELISA

3.12. Quantificação de Nitrito __ 23

4. Análise Estatística

5.1. Cultura de célula $B-1$

5.1.1. Citometria de fluxo: Pesquisa de célula B-1 em culturas de células peritoneais de camundongos Balb/c. 24

5.1.2. Deteç̧ão de IgM em cultura de célula B-1 24

5.1.3. Mediadores inflamatórios em cultura de Célula B-1 estimuladas com LPS. ___ 24

5.2. Cultura de Macrófagos (RAW 264.7) _ 25

5.3. Coculturas _ 25

5.3.1. Coculturas de macrófago (RAW 264.7) e célula B-1 (Balb/c)__ 25

5.3.2. Coculturas de Macrófagos (RAW 264.7) e células B-1 (C57IL-10\%)_ 27

5.4. Pesquisa de células B-1: Citometria de fluxo das células peritoneais de camundongos Balb/c e Balb/Xid

5.5. Perfil inflamatório de células peritoneais em cultura de Balb/c e Balb/Xid estimuladas com LPS

5.6. Modelo de Endotoxemia ___ 36

5.6.1. Curva de sobrevida ___ 36

5.6.2. Produção de mediadores inflamatórios em Balb/Xid e Balb/c após injeção de LPS. ___ 37

5.6.3. Perfil da produção de Nitrito em soro de animais Balb/c e Balb Xid após injeção de LPS __ 41

5.7. Inoculação de Célula B-1 (Balb/c) em peritônio de Balb/Xid _

5.7.1 Detecção de células B-1: Citometria de fluxo das células peritoneais de camundongos Balb/Xid reconstituídos com células B-1 (Balb/c) __ 42

5.7.2. Sobrevida dos animais Balb/Xid e Balb/Xid reconstituídos com célula B-1 (Balb/c) após injeção de LPS 43

6. Discussão 44

7. Conclusões 53 


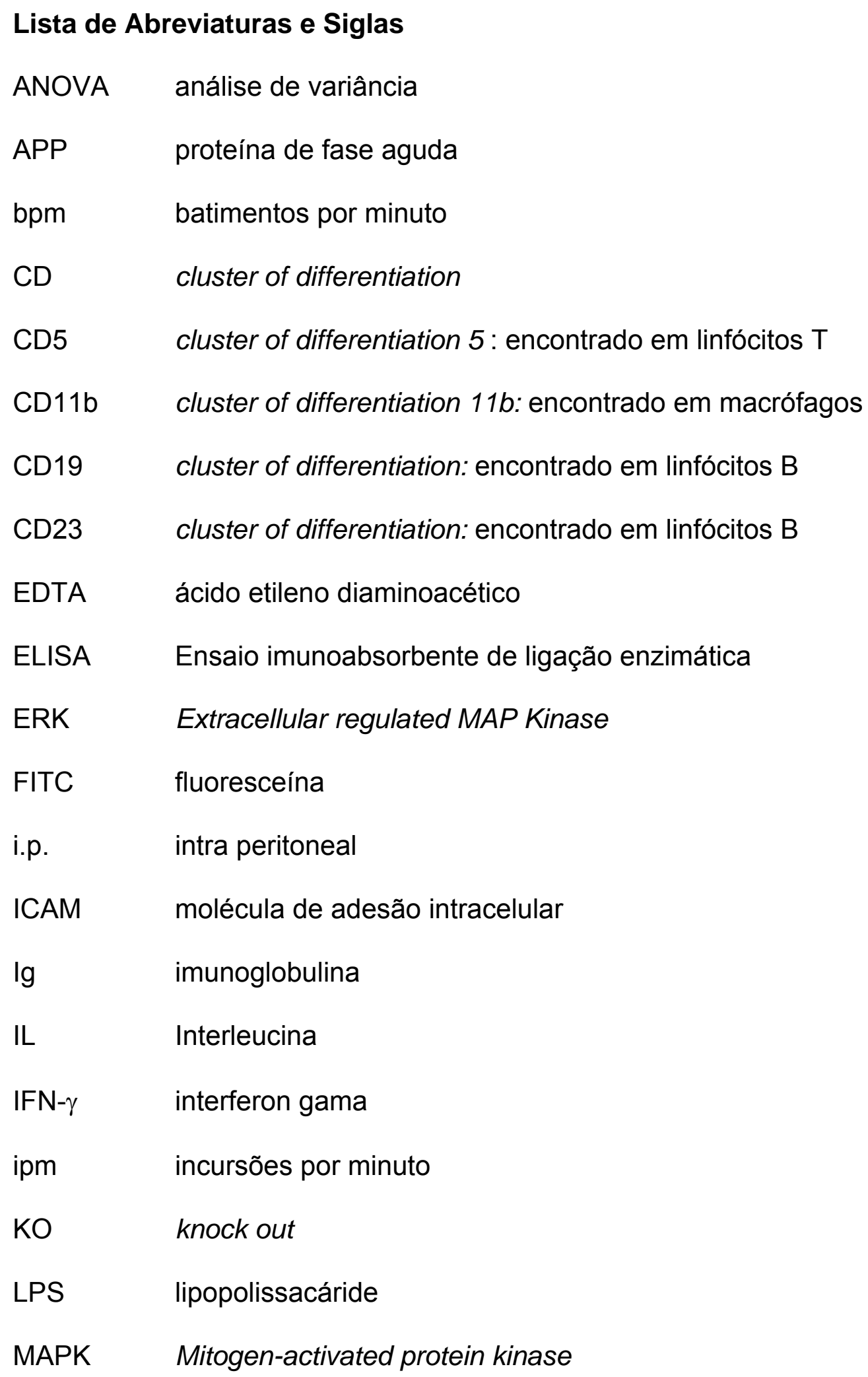




$\begin{array}{ll}\text { NFא } \beta & \text { Nuclear factor of Kappa light polypeptide gene enhancer in B cells } \\ \text { NO } & \text { óxido nítrico } \\ \text { NOS } & \text { óxido nítrico sintase } \\ \text { PBS } & \text { tampão fosfato salina } \\ \text { PCO }_{2} & \text { pressão (ou tensão) parcial do dióxido de carbono } \\ \text { p38 } & \text { p38 kinase } \\ \text { PE } & \text { ficoeritrina } \\ \text { PMSF } & \text { phenylmethylsufonil fluoride } \\ \text { SIRS } & \text { síndrome da resposta inflamatória sistêmica } \\ \text { TLR } & \text { receptores do tipo toll } \\ \text { TNF- } \alpha & \text { fator de necrose tumoral } \\ \text { UTI } & \text { unidade de terapia intensiva } \\ \text { VCAM } & \text { molécula de adesão de célula vascular } \\ \text { Xid } & \text { imunodeficiência ligada ao X } \\ \text { XLA } & \text { agamaglobulinemia ligada ao X }\end{array}$




\section{Lista de Figuras}

Figura-1 Esquema da obtenção das Células B-1 ................................... 16

Figura-2 Esquema do estímulo das células em cultura com LPS............. 17

Figura-3 Esquema da indução da endotoxemia por LPS........................ 19

Figura-4 TNF- $\alpha$, IL-6, IL-10 e nitrito em sobrenadantes de células B-1 (Balb/c), cultura de macrófagos (RAW264.7) e cocullturas de macrófagos (RAW264.7) e célula B-1 (Balb/c) após 24 hs de exposição ao LPS

Figura-5 TNF- $\alpha$, IL-6, IL-10 e nitrito em sobrenadantes de cocullturas de macrófagos (RAW264.7) e célula B-1 (IL-10 \%) após 24 hs de exposição ao LPS

Figura-6 Quantificação de TNF- $\alpha$ em sobrenadante de macrófago (RAW264.7) após estímulo com LPS e rlL-10

Figura-7 Quantificação de IL-6 em sobrenadante de macrófago (RAW264.7) após estímulo com LPS e rIL-10

Figura-8 Quantificação de Nitrito em sobrenadante de macrófago (RAW264.7) após estímulo com LPS e rlL-10

Figura-9 Pesquisa de célula B-1 em peritônio de camundongos das linhagens Balb/c e Balb/Xid

Figura-10 TNF- $\alpha$, IL-6, IL-10 e nitrito em sobrenadantes de cultura de células peritoneais de Balb/c e Balb/Xid após 24 hs de exposição ao LPS 


\section{Lista de Figuras (continuação)}

Figura-11 Sobrevida dos animais das linhagens Balb/c e Balb/Xid após injeção de LPS

Figura-12 Perfil inflamatório em soro dos animais após a injeção de LPS

Figura-13 Perfil inflamatório em pulmão dos animais após a injeção de LPS

Figura-14 Perfil inflamatório em intestino dos animais após a injeção de LPS

Figura-15 Concentrações de nitrito no soro entre linhagens Balb/c e Balb/Xid após 1,5; 4 e 6 horas após injeção de LPS

Figura-16 Pesquisa de células B-1 em peritônio de camundongos Balb/Xid repopulados

Figura-17 Sobrevida de animais Balb/Xid e Balb/Xid inoculados com célula B-1 (WT) após injeção de LPS 


\section{Resumo}

A sepse é a Síndrome da Resposta Inflamatória Sistêmica decorrente de uma infecção por gram positivos/negativos, fungos ou vírus. É caracterizada por alta liberação de mediadores inflamatórios podendo levar à morte. As células B-1 são encontradas em cavidades peritoneal e pleural de camundongos e sua origem e função ainda não são completamente conhecidas. Apresentam marcadores de superfície de linhagem mielóide e linfóide e migram para focos inflamatórios comportando-se como macrófagos. Objetivo: investigar o papel da célula B-1 na resposta inflamatória após estímulo com lipopolissacáride (LPS) in vitro e in vivo. Métodos: TNF- $\alpha$, IL-6, IL-10 (ELISA) e nitrito (Griess) foram dosados em sobrenadante de cultura celular $\left(10^{6} \mathrm{cel} . / \mathrm{ml}\right)$. As células em cultura receberam por 24h de estímulo com $10 \mu \mathrm{g} / \mathrm{mL}$ de LPS de Escherichia coli (026:B6 Sigma ${ }^{\circledR}$ ). Foram realizados os seguintes grupos cultura de célula B-1 (Balb/c), cultura de macrófagos de linhagem (RAW 264.7) coculturas (macrófagos de linhagem RAW 264.7 e células B-1 (Balb/c, C57BL/6 e C57BL/6 IL-10 \%), e células peritoneais de camundongos Balb/c e Balb/Xid (imunodeficiente em célula B-1) A endotoxemia foi induzida com injeção de LPS 15 mg/kg (i.p.) em camundongos Balb/c e Balb/Xid. Foram quantificados, TNF- $\alpha$, IL-6, IL-10 e nitrito em soro, pulmão e intestino dos animais após 1,5, 4 e 6 horas após a injeção de LPS. Ensaios de inoculação de células B-1 (Balb/c) em camundongos Balb/Xid foram realizados, e curva de sobrevida foi analisada após indução de endotoxemia. Resultados: Após o estímulo com LPS, células B-1 produziram IL-10 e a presença destas células em 
cocultura com macrófago promoveu a diminuição na produção de TNF- $\alpha$, IL-6, Nitrito e aumento de IL-10. Contudo, célula B-1 (IL-10 \%) em cocultura com macrófagos, não inibem a produção de mediadores pro inflamatórios. Análise com macrófagos peritoneais de camundongo Balb/Xid e Balb/c após estímulo com LPS em cultura mostrou reprodução do fenômeno encontrado com os experimentos com cultura de célula imortalizada, isto é, maior produção de TNF- $\alpha$, IL-6 e NO em Balb/Xid (B-1 deficiente). Os estudos in vivo mostraram $60 \%$ de mortalidade em camundongo Balb/Xid comparando com Balb/c (0\%) após 16 horas de injeção de LPS. Nos animais Balb/Xid encontramos padrão pro inflamatório exacerbado com maiores concentrações de TNF- $\alpha$, IL-6 e menores concentrações de IL-10 no plasma e tecidos quando comparamos com Balb/c. Conclusões: Nossos dados mostraram que a presença de células B-1 promoveram diminuição de mediadores pro inflamatórios e aumento de IL-10 em coculturas com macrófagos e que a modulação da resposta inflamatória pode ser devida a secreção de IL-10 pela célula B-1. Este padrão de resposta pro inflamatória se repete in vivo e é a possível causadora da maior taxa de mortalidade em camundongos da linhagem Balb/Xid. 
Summary

Sepsis syndrome is caused by inappropriate immune activation due to bacteria and bacterial components released during infection. This syndrome is the leading cause of death in intensive care units. Specialized B-lymphocytes located in the peritoneal and pleural cavities are known as B-1 cells. These cells produce $\lg M$ and IL-10, both of which are potent regulators of cell-mediated immunity. It has been suggested that B-1 cells modulate the systemic inflammatory response in sepsis. In this study, we conducted in vitro and in vivo experiments in order to investigate a putative role of B-1 cells in a murine model of LPS-induced sepsis. Macrophages and B-1 cells were studied in monocultures and in co-cultures. The B-1 cells produced the anti-inflammatory cytokine IL-10 in response to LPS. In the B-1 cell-macrophage co-cultures, production of proinflammatory mediators (TNF- $\alpha$, IL-6 and nitrite) was lower than in the macrophage monocultures, whereas that of $\mathrm{IL}-10$ was higher in the co-cultures. Co-culture of $\mathrm{B}-1 \mathrm{IL}-10^{-/-}$cells and macrophages did not reduce the production of the proinflammatory mediators (TNF- $\alpha$, IL-6 and nitrite). After LPS injection, the mortality rate was higher among Balb/Xid mice, which are B-1 cell deficient, than among wild-type mice $(65.0 \%$ vs. $0.0 \%$ ). The Balb/Xid mice also presented a proinflammatory profile of TNF-a, IL-6 and nitrite, as well as lower levels of IL-10. In the early phase of LPS stimulation, B-1 cells modulate the macrophage inflammatory response, and the main molecular pathway of that modulation is based on IL-10-mediated intracellular signaling. 


\section{Introdução}

\subsection{Síndrome da Resposta Inflamatória Sistêmica (SIRS) e Sepse}

De acordo com a American College of Chest Physicians/ Society of Critical Care Medicine Consensus Conference (ACCP/SCCM), conferência realizada em 1991 com o objetivo de estabelecer uma definição prática da sepse, o termo Síndrome da Resposta Inflamatória Sistêmica (SIRS) ficou definido por resposta inflamatória desencadeada pelo organismo frente a qualquer agressão, infecciosa ou não infecciosa, tais como pancreatite, queimaduras, isquemia, trauma ou choque hemorrágico. É caracterizada pela associação de pelo menos dois dos seguintes parâmetros: hipotermia (temperatura corpórea menor que $36^{\circ} \mathrm{C}$ ) ou febre (temperatura acima de $38^{\circ} \mathrm{C}$ ), taquicardia (freqüência cardíaca acima de 90 bpm), taquipinéia (freqüência respiratória acima de $20 \mathrm{ipm}$ ou $\mathrm{pCO}_{2}$ abaixo de 32 $\mathrm{mmHg}$ ), leucocitose (leucócitos acima de $12 \times 10^{9}$ cél./L), leucopenia (abaixo de $4 \times 10^{6}$ cél./L). A presença de microorganismos em tecidos normalmente estéreis é definida como infecção e a sepse é caracterizada por resposta inflamatória sistêmica apresentando os eventos da SIRS, acompanhada de infecção que pode ser de origem bacteriana (gram positivas/gram negativas), vírus, fungos ou parasitas [1, 2].

O agravamento do quadro de sepse, denominado sepse grave, é caracterizado por anormalidades de perfusão, disfunção orgânica e hipotensão responsivos a hidratação vigorosa. O choque séptico ocorre quando a hipotensão é irresponsiva a hidratação vigorosa, levando a disfunção orgânica e anormalidades de perfusão. A lesão de órgãos pode culminar na síndrome de insuficiência de múltiplos órgãos que acarreta na função orgânica anormal em 
pacientes gravemente doentes onde a homeostase não pode ser mantida sem a intervenção de aparelhos [2, 3].

Apesar do desenvolvimento de novos antibióticos e aprimoramento de medidas de tratamento intensivo, a taxa de mortalidade da sepse ainda permanece alta. O tratamento permanece de suporte e direcionado para o controle da infecção e correção de distúrbios hemodinâmicos [4-6]. A sepse grave e o choque séptico estão associados a taxas de mortalidade de 40 a $60 \%$ [7]. Sepse, SIRS e choque séptico juntos representam a causa mais importante de morte em UTI de adultos [8].

As novas estratégias propostas para o tratamento da sepse (inibidores da endotoxina, inibidores de citocinas e bloqueadores de síntese de óxido nítrico [9], não demonstraram benefício em diminuir a mortalidade em ensaios clínicos.

O sistema imunológico dispõe de uma ampla gama de células e substâncias para a proteção contra agentes infecciosos. Vários tipos celulares tais como monócitos, macrófagos, linfócitos, neutrófilos e células endoteliais participam da resposta inflamatória exacerbada existente na sepse liberando uma grande variedade de mediadores. Os monócitos e macrófagos liberam citocinas pró-inflamatórias como TNF- $\alpha$ e IL-1. Os linfócitos T podem apresentar duas polarizações: T helper 1 (Th1) e T helper 2 (Th2). O padrão Th1 é caracterizado pela secreção de IFN $\gamma$, TNF- $\alpha$, IL-12 e no padrão Th2 há a liberação de IL4 e IL10 [10]. Além destes mediadores, proteínas de fase aguda, ativação do sistema de coagulação, sistema complemento e aumento da produção do óxido nítrico estão 
relacionados aos efeitos deletérios da sepse tanto em pacientes como nos modelos experimentais [11-13].

\subsection{Detecção do invasor e sinalização intracelular}

O lipopolissacáride (LPS) é uma toxina que compõe a membrana externa da bactéria gram negativa e é capaz de ativar células do sistema imunológico ativando fatores responsáveis pela produção de mediadores inflamatórios resultando na endotoxemia ou choque endotoxêmico [14].

O LPS induz inflamação local e sistêmica e muitas das manifestações clínicas, tais como febre, hipercoagulação e hipotensão periférica e lesão tecidual observadas em infecções por bactérias gram-negativas podem ser mimetizadas pela administração de LPS [15].

O sistema imunológico inato é o maior responsável pelo mecanismo de defesa e vigilância contra a invasão de patógenos através de receptores conservados evolutivamente, também conhecidos como do tipo Toll (TLR) [16].

O LPS é um ativador de células mononucleares, células endoteliais, polimorfonucleares e de particular importância os monócitos e macrófagos e a resposta celular envolve o sistema LBP/CD14/receptor de mamíferos semelhante ao Toll-4 [17, 18].

A ativação dos macrófagos pelo LPS se dá através da ligação à proteína ligante de LPS (LBP) e interage com o CD 14 (proteína da superfície externa da membrana celular de monócitos que facilita a ativação celular induzida pelo LPS).

O CD14 em conjunto com a proteína MD2 participam na apresentação de LPS para o receptor similar ao Toll tipo 4 (TLR4). Após esta interação, o fator de 
transcrição nuclear $N F \kappa \beta$ migra para o núcleo atingindo a região promotora do DNA, ativando assim a produção de mRNA e posterior produção de proteínas envolvidas no processo inflamatório tais como fator de necrose tumoral-alfa (TNF$\alpha$ ), moléculas de adesão (ICAM e VCAM) e interleucinas (IL) tais como IL-1, IL-6, IL-8 e IL-10 [14, 19].

\subsection{Sinalização intercelular}

As citocinas, proteínas de fase aguda, mediadores lipídicos (prostaglandinas, e leucotrienos) e os componentes plasmáticos (cininas, fatores de coagulação e complemento) também participam do desenvolvimento da sepse, levando a migração e ativação celular, vasodilatação, agregação plaquetária e ao aumento da permeabilidade vascular [20].

As citocinas são mediadores inflamatórios produzidas por células do sistema imunológico que regulam as funções de diversas células. Seus efeitos podem ser locais ou sistêmicos e incluem indução de proliferação celular, quimiotaxia, apoptose e diferenciação celular [11, 13].

O evento central na cascata fisiopatológica da endotoxemia é a liberação sistêmica excessiva de citocinas inflamatórias, tais como, Fator de Necrose Tumoral - alfa (TNF- $\alpha$ ), interleucinas IL-1 $\beta$, IL-6, IL-12, IL-18, e interferon- $\gamma$ (IFN $\gamma$ ) em resposta ao LPS. 


\subsubsection{Fator de Necrose Tumoral alfa (TNF- $\alpha$ )}

O TNF- $\alpha$ é produzido principalmente por macrófagos e células T após estímulo por LPS e é considerado um potente ativador de macrófagos, neutrófilos e células endoteliais. Além disso, o TNF- $\alpha$ está relacionado com produção de proteínas de fase aguda pelo fígado, apoptose, hipotensão, anorexia, diminuição do fluxo sanguineo, dano a mucosa intestinal, alteração no perfil lipídico e aumento da coagulação [21-23].

Elevadas concentrações de TNF- $\alpha$ tem se relacionado com mortalidade em estudos experimentais de sepse com bactérias gram-positivas ou gram-negativas e que a neutralização do TNF- $\alpha$ antes da inoculação de LPS ou bactérias em animais se mostrou benéfica [24, 25].

Em ensaios clínicos, a infusão de anticorpos anti-TNF- $\alpha$ em pacientes com sepse grave e choque séptico mostrou resultados pouco satisfatórios não promovendo diminuição da mortalidade [26-28].

\subsubsection{Interleucina-6 (IL-6)}

A IL-6 é secretada principalmente por células endoteliais, macrófagos e células T. Promove a síntese de proteínas de fase aguda pelo fígado e estimula a produção de anticorpos pelas células B. Esta citocina apresenta melhor correlação com a mortalidade tanto em modelos experimentais como em pacientes com sepse $[26,28]$. 


\subsubsection{Interleucina-10 (IL-10)}

A IL-10 é produzida por macrófagos e células T (Th2) e tem a função de suprimir a atividade microbicida de macrófagos pela inibição da produção de IFN$\gamma$, óxido nítrico sintases, radicais livres, prostaglandinas, atividade de metaloproteinases e apresentação de antígenos. Paradoxalmente, esta interleucina está relacionada com o aumento da produção de anticorpos pela célula B [29].

Em estudos em modelos experimentais de sepse, a IL-10 está relacionada com a diminuição da mortalidade [12, 24].

\subsection{4. Óxido Nítrico}

O óxido nítrico (NO) é um radical livre considerado um dos mais importantes mediadores de processos intra e intercelulares podendo desempenhar tanto um papel protetor quanto prejudicial ao organismo. Este radical é produzido a partir da L-arginina, por uma reação mediada pelas enzimas NO sintase constitutivas (cNOS) e induzível (iNOS ou NOS2) O grupo da cNOS se subdivide em: NOS1 ou nNOS (expressa em células neuronais), NOS3 ou eNOS (expressa pelo endotélio) [30].

O NO produzido constitutivamente desempenha um papel crucial na proteção do vaso sanguineo e está relacionada à manutenção do tônus vascular, regulação da pressão sanguinea prevenção da agregação plaquetária, inibição da adesão de neutrófilos e monócitos ao endotélio vascular [31-33]. 
A iNOS não é expressa sob condições normais, é induzida por citocinas e ou endotoxinas em uma variedade de células tais como macrófagos, células endoteliais, linfócitos T, miócitos, hepatócitos, neutrófilos e plaquetas. O NO produzido através desta ativação possui ação citotóxica levando a destruição de microorganismos, parasitas e células tumorais [30].

Em resposta a ação do LPS e citocinas inflamatórias, a produção de óxido nítrico é aumentada provocando relaxamento da musculatura vascular lisa e queda da resistência arterial sistêmica o que consiste numa característica das fases iniciais do choque séptico [2].

A produção exacerbada de NO pelos miócitos cardíacos ativados por citocinas e pelas células da musculatura lisa vascular, leva à falência cardíaca e à perda da pressão de perfusão respectivamente, resultando em choque hemodinâmico [34-36].

As grandes quantidades de NO e superóxido presentes na sepse propiciam a formação de peroxinitrito, agente altamente reativo e responsável pela lesão celular e tecidual.

\subsection{Células participantes da resposta inflamatória}

Dentre os vários tipos celulares que participam da resposta inflamatória tais como: macrófagos, neutrófilos, células endoteliais, células dendríticas, linfócitos B e T. Destacamos os linfócitos B que exercem um importante papel na regulação do sistema imunológico pela produção de anticorpos, apresentação de antígenos, interação celular e produção de citocinas. 


\section{5.- Célula B-1}

As células B-1 são um subgrupo dos linfócitos B que apresentam características específicas que as diferem dos linfócitos B convencionais por apresentarem em sua superfície marcadores de linhagem mielóide (Mac-1) e linfóide (linfócito T-CD5 e linfócito B - IgM, IgD e CD19) que as diferenciam dos outros linfócitos [37, 38]. Em camundongos neonatos, essas células se originam no fígado fetal e, em uma proporção menor, na medula óssea. Em animais adultos são encontradas em grande número no peritônio, como uma população que se auto-renova e secretam anticorpos IgM espontaneamente [39].

As células B-1 são subclassificadas em B-1a (CD5+) e B-1b (CD5-) [40]. De acordo com Almeida e colaboradores [39] as células B-1, principalmente as B-1b estão presentes no sobrenadante de cultura estacionária de células peritoneais aderentes. Também já foi demonstrado que as células B-1 migram para focos inflamatórios não específicos, aderem ao vidro, diferenciam-se em células fenotipicamente semelhantes a macrófagos e secretam IgM [39, 41].

Desde a descoberta da célula B-1, muitos estudos têm sido feitos com o intuito de elucidar a origem e função destas células, pois não se sabe se as células B-1 possuem função especial na resposta imunológica. Uma possibilidade é que as células B-1 forneçam uma fonte de produção rápida de anticorpos contra microorganismos presentes em sítios particulares, como o peritônio [42-45].

Apesar de a função das células B-1 ainda não estar definida Popi e colaboradores [41] sugerem atividade modulatória dessas células sobre a atividade efetora de outras células, tais como macrófagos. 


\subsection{Características clínicas da imunodeficiência de linfócitos $B$}

Em humanos, mutações no gene que codifica a enzima tirosina quinase de Bruton resultam numa doença chamada agamaglobulinemia ligada ao X (XLA), que é caracterizada pela deficiente maturação das células B [46]. Esta doença está associada a ausência ou diminuição de produção de anticorpos e maior susceptibilidade a infecções recorrentes $[47,48]$.

Em camundongos denominados Xid, mutações localizadas no cromossomo X (imunodeficiência ligada ao $X$ ) acarretam na imunodeficiência de célula $B$, especialmente em célula B-1 na cavidade peritoneal [49].

Essas constatações reforçam a idéia de que as células B possuem papel relevante na resposta inata e adquirida, uma vez que a deficiência deste tipo celular predispõe indivíduos a infecções. 


\section{Objetivos}

\section{Objetivo Geral:}

Investigar in vitro e in vivo a participação da célula B-1 na resposta inflamatória ao Lipopolissacáride (LPS);

\section{Objetivos secundários:}

- Caracterizar a produção de mediadores inflamatórios em cultura de célula B-1 antes e após exposição ao LPS;

- Investigar o envolvimento da célula B-1 na resposta inflamatória de macrófagos estimulados por LPS in vitro em:

-Coculturas de macrófagos de linhagem (RAW264.7) com célula B-1.

-Células peritoneais dos camundongos Balb/c e Balb/Xid;

- Investigar o envolvimento da célula B-1 em modelo de endotoxemia por LPS em camundongos da linhagem Balb/Xid e Balb/c;

-Estudo de sobrevida dos animais após a injeção de LPS;

-Traçar o perfil inflamatório no soro e tecidos dos animais após a injeção de LPS; 


\section{Materiais e Métodos}

Este projeto (1138/05) foi aprovado pela a Comissão de Avaliação de Projetos de Pesquisa (CAPEPesq) da Faculdade de Medicina da Universidade de São Paulo.

Camundongos machos de 6 a 8 semanas ( 23 a 26 gramas) das seguintes linhagens foram utilizados neste estudo:

- Balb/c: fornecidos pelo Biotério da Faculdade de Medicina da Universidade de São Paulo (FMUSP).

- Balb/Xid: fornecidos pelo Biotério do Instituto de Ciências Biomédicas da Universidade de São Paulo (ICB-USP).

- C57 BL/6: fornecidos pelo Biotério da Faculdade de Medicina da Universidade de São Paulo (FMUSP).

- C57BL/6 IL-10\%: fornecidos pelo Biotério do Instituto de Ciências Biomédicas da Universidade de São Paulo (ICB-USP).

Os animais foram mantidos sob temperaturas entre 22 a $25^{\circ} \mathrm{C}$, sem restrição hídrica ou dietética (ad libitum) e ciclo claro/escuro controlados. Todas as linhagens foram utilizadas no estudo in vitro enquanto que somente as linhagens Balb/c e Balb/Xid foram utilizadas no estudo in vivo. 


\subsection{Cultura de células}

\subsubsection{Células peritoneais aderentes}

Camundongos Balb/Xid e Balb/c foram sacrificados com éter etílico e submetidos à laparotomia em fluxo laminar $\left(\mathrm{VECO}^{\circledR}\right)$. As células foram coletadas da cavidade peritoneal por lavagens com meio de cultura RPMI-1640 (Sigma ${ }^{\circledR}$ ). Células viáveis (não coradas por azul de Trypan - Invitrogen ${ }^{\circledR}$ ) foram distribuídas, em placas de cultura de 12 poços $\left(\operatorname{Costar}^{\circledR}\right)$ a uma concentração de $1 \times 10^{6}$ células $/ \mathrm{mL}$ e incubadas em RPMI a $37^{\circ} \mathrm{C}$ por 1 hora em estufa de $\mathrm{CO}_{2}$. Após a incubação, o sobrenadante foi descartado, a placa lavada com tampão fosfato salina (PBS-137mM NaCl; 2,7mM KCl, 8,1 $\mathrm{mM} \mathrm{Na}_{2} \mathrm{HPO}_{4}, 1,5 \mathrm{mM} \mathrm{KH}_{2} \mathrm{PO}_{4}, \mathrm{pH} 7,3$ ) para a eliminação das células não aderentes e $1 \mathrm{~mL}$ de meio R10 (RPMI-1640 Sigma $^{\circledR}$ acrescido com $10 \%$ de soro fetal bovino - Invitrogen ${ }^{\circledR}$ ) foi acrescentado às culturas que ficaram mantidas a $37^{\circ} \mathrm{C}$ por 24 horas em estufa de $\mathrm{CO}_{2}$.

\subsubsection{Cultura de macrófagos}

A linhagem de macrófagos RAW 264.7 (American Type Culture Collection ATCC- TIB 71) proveniente de camundongo Balb/c foi cultivada em meio RPMI acrescido de $10 \%$ de soro fetal bovino. O cultivo das células foi realizado em garrafas de cultura de $75 \mathrm{~cm}^{2}\left(\right.$ Costar $\left.^{\circledR}\right)$ e o subcultivo foi realizado com o uso de raspador de placa para o descolamento das células a cada 3 dias. Para a realização dos experimentos, foram plaqueadas $1 \times 10^{6}$ células $/ \mathrm{mL}$ (macrófagos 
isolados) e $5 \times 10^{5}$ células $/ \mathrm{mL}$ (coculturas com células $\mathrm{B}-1$ ) em placas de 12 poços com $1 \mathrm{~mL}$ de meio $\mathrm{R} 10$ a $37^{\circ} \mathrm{C}$ por 24 horas em estufa de $\mathrm{CO}_{2}$.

\subsubsection{Cultura de células B-1}

As células B-1 foram cultivadas a partir de células peritoneais provenientes de camundongos Balb/c, C57 BL/6 e C57 BL/6 IL-10\% coletadas conforme descrito em 3.1.1., semeadas em placas de vidro com $90 \mathrm{~mm}$ de diâmetro e incubadas a $37^{\circ} \mathrm{C}$ por 1 hora em estufa de $\mathrm{CO}_{2}$. Após a incubação, o sobrenadante foi descartado e a placa lavada com PBS para a eliminação das células não aderentes.

As células aderentes foram mantidas em cultura com meio R10 por 5 dias sem trocas de meio de cultura. Após os 5 dias as células do sobrenadante foram coletadas, centrifugadas e distribuídas em placas de 12 poços a uma concentração de $1 \times 10^{6}$ células $/ \mathrm{mL}$ em meio $\mathrm{R} 10$. A figura 1 mostra os passos para a obtenção das células B-1 a partir de cultura de células peritoneais de camundongos.

As células B-1 obtidas de camundongo Balb/c foram utilizadas para análise de citometria de fluxo, quantificação de lgM, exposição ao LPS isoladamente e em coculturas com macrófagos RAW 264.7 e inoculação em peritônio de camundongo Balb/Xid.

As células B-1 provenientes de camundongos C57BL/6 e C57BL/6 IL-10\% foram utilizadas em coculturas com macrófagos RAW 264.7. 


\subsubsection{Coculturas de macrófagos e células B-1}

Após 24 horas do plaqueamento dos macrófagos RAW $264.7\left(5 \times 10^{5}\right.$ células $/ \mathrm{mL})$, o meio de cultura foi trocado e células B-1 $\left(5 \times 10^{5}\right.$ células $\left./ \mathrm{mL}\right)$ provenientes de camundongos Balb/c ou C57 BL/6 ou C57 BL/6 IL-10\%.foram acrescentadas totalizando $1 \times 10^{6}$ células $/ \mathrm{mL} /$ poço.

\subsection{Estímulo das células com LPS in vitro}

Culturas celulares provenientes de lavados peritoneais dos camundongos, células B-1 (Balb/c), macrófagos (RAW 264.7) e coculturas (macrófagos RAW 264.7 e célula B-1 proveniente de Balb/c, C57 BL/6 e C57 BL/6 IL-10\%.) foram distribuídas em placas de cultura de células de 12 poços. Após 24 horas do plaqueamento, o meio de cultura R10 foi trocado por RPMI contendo LPS de Escherichia coli (026:B6 Sigma ${ }^{\circledR}$ ) a uma concentração de 10 $\mu \mathrm{g} / \mathrm{mL}$ (figura 2). Após 24 horas de exposição, os sobrenadantes foram coletados e armazenados em freezer $-80^{\circ} \mathrm{C}$ para posterior análise. A produção de mediadores inflamatórios foi realizada pela técnica de ELISA (TNF- $\alpha$, IL-6 e IL-10) e nitrito pelo método de Griess. Células não expostas ao LPS foram utilizadas como controle.

\subsection{Estímulo de macrófagos (RAW 264.7) com IL-10 recombinante (rIL-10)}

As células foram ressuspensas numa concentração de $1 \times 10^{6} / \mathrm{mL}$ e distribuídas em placa de 96 poços com um volume final, por poço, de $200 \mu \mathrm{L}$. Após 24 horas do plaqueamento, o meio de cultura R10 foi trocado por RPMI 
contendo LPS de Escherichia coli (026:B6 Sigma $\left.{ }^{\circledR}\right)$ a uma concentração de $10 \mu \mathrm{g} / \mathrm{mL}$ e doses crescentes de rlL-10 (R\&D Systems) foram acrescentadas (150, 300, 600 e $1200 \mathrm{pg} / \mathrm{mL}$ ). Após 24 horas de exposição, os sobrenadantes foram coletados e armazenados em freezer $-80^{\circ} \mathrm{C}$ para posterior análise. A produção de mediadores inflamatórios foi realizada pela técnica de ELISA (TNF- $\alpha$, IL-6 e IL-10) e nitrito pelo método de Griess. Células não expostas ao LPS foram utilizadas como controle. 


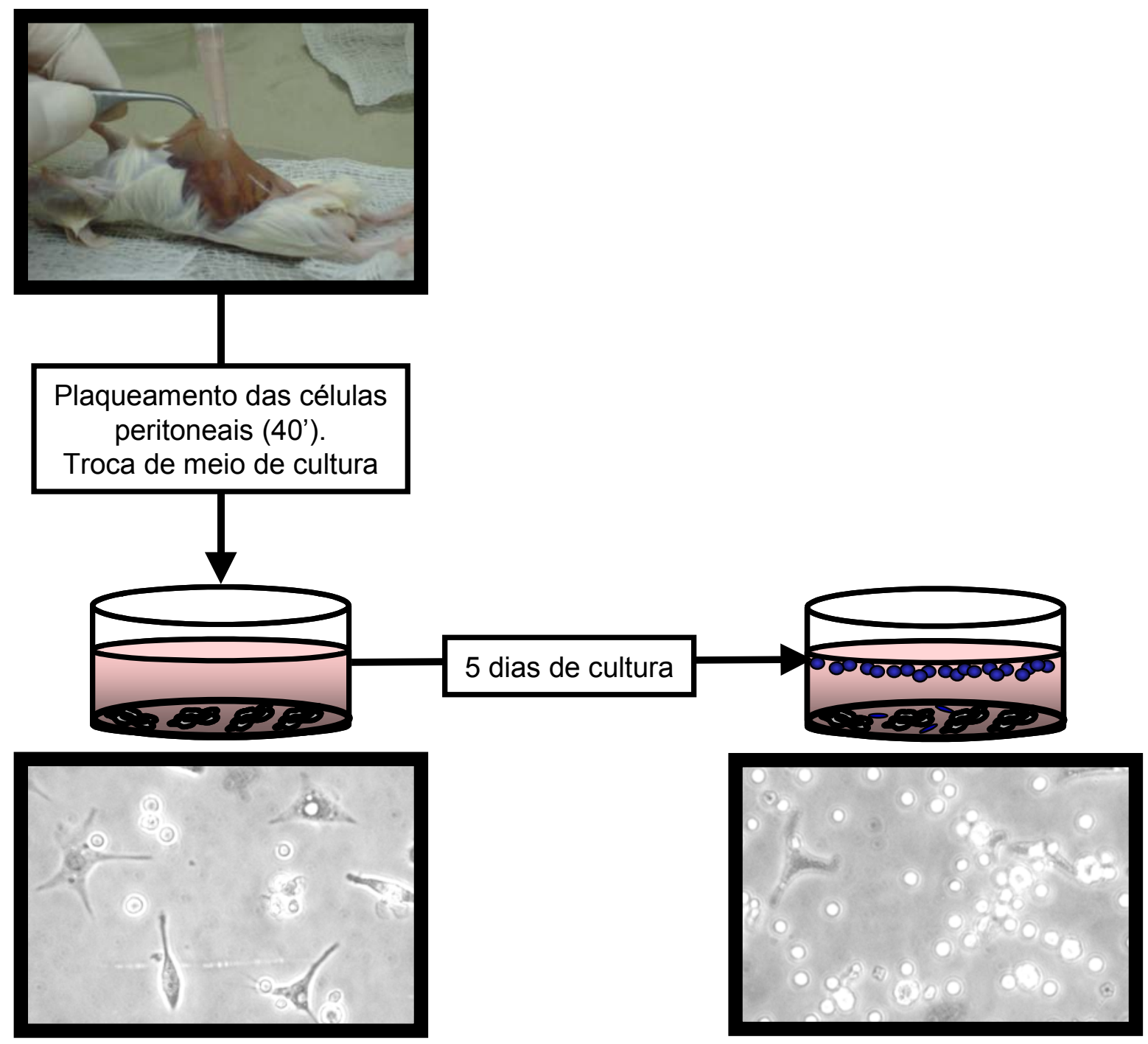

Figura 1- Esquema da obtenção e cultivo de células B-1. As células peritoneais são retiradas por lavagens com meio de cultura RPMI e plaqueadas por 40 minutos. Na troca do meio de cultura as células não aderentes são retiradas e pós 5 dias, as células B-1 são coletadas através da aspiração do sobrenadante das culturas. 


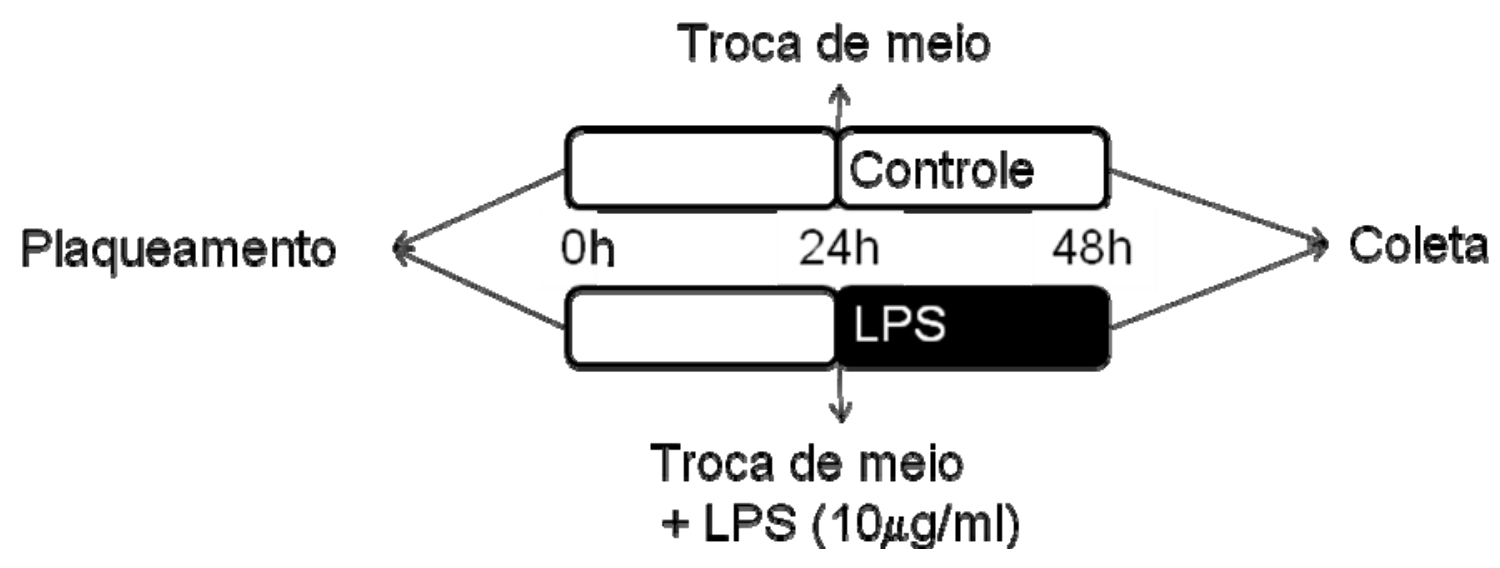

Figura 2- Esquema do estímulo das células em cultura com LPS. 


\subsection{Modelo de Endotoxemia}

A endotoxemia foi induzida em camundongos da linhagem Balb/Xid e Balb/c por injeção de LPS Escherichia coli (026:B6 Sigma $\left.{ }^{\circledR}\right)$ 15mg/kg intra peritoneal (i.p.) como descrito por Jagtap e colaboradores [50].

\subsection{Mediadores inflamatórios no modelo de endotoxemia}

Com o intuito de avaliar a resposta inflamatória, dezoito animais de cada linhagem receberam injeção de LPS e foram separados em três grupos de seis animais os quais foram sacrificados 1,5; 4 e 6 horas após o estímulo. (Figura-3). 0 grupo controle foi composto por seis animais que receberam solução fisiológica (i.p.). Soro, pulmão e intestino foram colhidos e armazenados em freezer $-80^{\circ} \mathrm{C}$ para posterior análise. Os mediadores inflamatórios (TNF- $\alpha$, IL-6 e IL-10) foram dosados em soro, pulmão e intestino pelo método de ELISA. A produção de nitrito (subproduto do óxido nítrico) foi investigada no soro dos animais em estudo pelo método de Griess. 


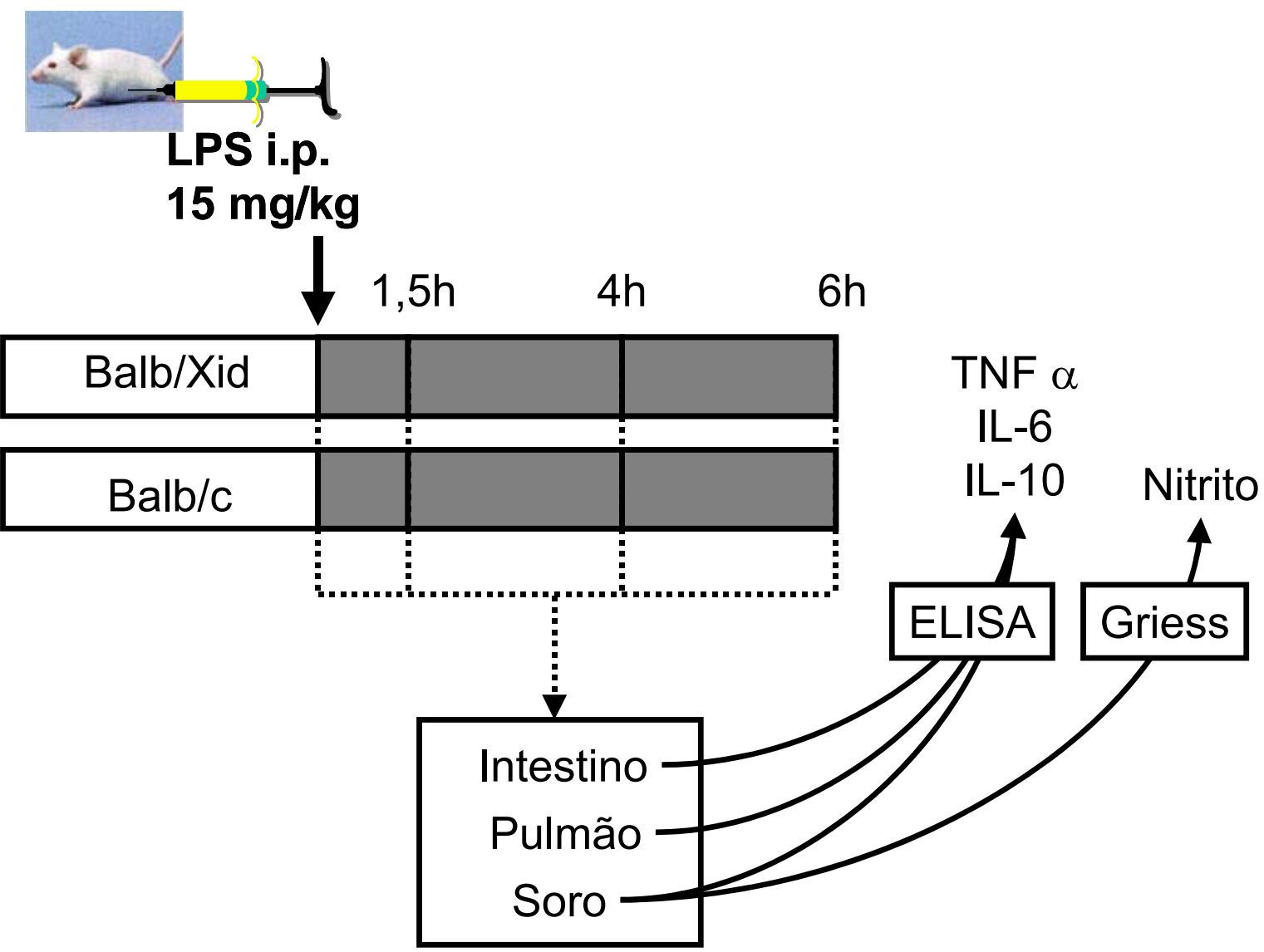

Figura 3- Esquema da indução de endotoxemia por LPS e coleta de amostras para quantificação dos mediadores inflamatórios.

\subsection{Inoculação de Célula B-1 (Balb/c) em peritônio de Balb/Xid}

Com o intuito de verificar se há reconstituição de células B-1 no peritônio de camundongos Balb/Xid, células B-1 (provenientes de cultura de células peritoneais de camundongo Balb/c) foram inoculadas nesses animais (via i.p.) nas concentrações de $5 \times 10^{5}$ e $1 \times 10^{6}$ (n=3 por concentração). Após 7 dias da inoculação, os animais foram sacrificados e as células peritoneais foram coletadas e analisadas por citometria de fluxo para pesquisa de células B-1. 


\subsection{Curva de Sobrevida}

Após a injeção de LPS, animais das linhagens Balb/c $(n=12)$ e Balb/Xid $(n=12)$ e Balb/ Xid repopulados com célula B-1 $\left(1 \times 10^{6}\right.$ células $\left./ \mathrm{mL}\right)$ foram observados e os óbitos foram registrados a cada 12 horas.

\subsection{Detecção de células B-1: Citometria de Fluxo}

A pesquisa de células B-1 por citometria de fluxo foi realizada em células peritoneais de camundongos Balb/c, Balb/Xid e de cultura de célula B-1 proveniente de sobrenadante de cultura de células peritoneais de camundongo Balb/c após 5 dias de cultivo adquiridas como descrito anteriormente (3.1.3.). As células foram ajustadas a uma concentração de $1 \times 10^{6}$ células $/ \mathrm{ml}$, centrifugadas e ressuspensas em $100 \mu \mathrm{l}$ de PBS-BSA 1\%. Cada alíquota foi incubada previamente com anti CD16/CD32 para bloqueio do receptor Fcy II e III. Os tubos foram mantidos a $4^{\circ} \mathrm{C}$ por 30 minutos.

Após a incubação, as células foram lavadas, ressuspensas novamente em PBS-BSA $1 \%$ e cada alíquota incubada com os anticorpos monoclonais adequados para análise dos marcadores de superfície. Foram utilizados os antiCD19 de camundongo feito em rato conjugado a PE, anti CD-23 de camundongo feito em rato e biotinilado, anticorpo anti CD11b e anticorpo anti CD5.

As células foram incubadas com os anticorpos marcados com os fluorocromos por 1 hora e gelo. Após a incubação, as células foram lavadas e ressuspensas em $1 \mathrm{~mL}$ de paraformoldeído $1 \%$ por 1 hora. Para a análise das 
amostras pelo citômetro de fluxo, as células foram centrifugadas, ressuspensas em $1 \mathrm{~mL}$ de PBS e colocadas em tubo apropriados e mantidos no gelo.

A análise foi realizada e as células B-1 apresentaram marcação: CD11 b+, $\mathrm{CD}^{+} 9^{+}, \mathrm{CD}^{-}$e CD23.

\subsection{Detecção de IgM em cultura de célula B-1.}

A detecção de IgM em culturas de células B-1 estimuladas ou não com LPS foi realizada pelo método de imunoturbidimétrico. Neste método, a imunoglobulina M reage com o anticorpo específico formando imunocomplexos insolúveis. A turbidez produzida pelos imunocomplexos é proporcional à concentração de lgM.

A reação ocorreu com $60 \mu \mathrm{l}$ de amostra acrescida de $900 \mu \mathrm{l}$ de tampão e $100 \mu \mathrm{l}$ de anti-soro anti- IgM. Após incubação de 30 minutos, a absorbância foi determinada por leitor de ELISA (Genius - TECAN) com filtro de 340nm.

\subsection{Preparo das amostras de pulmão e intestino para dosagem de TNF- $\alpha$, IL-6 e IL-10 por ELISA}

A extração protéica dos pulmões e intestino foi realizada através da pulverização em gral de aço inoxidável e pistilo de cerâmica em nitrogênio líquido e ressuspensos em $1 \mathrm{~mL}$ de tampão de lise de proteínas (NP40- NP40 10\%; glicerol 10\%; $\mathrm{NaCl} 135 \mathrm{mM}$; Tris 20mM; PMSF 1mM). As amostras foram homogeneizadas em agitador tipo gangorra por 1 hora em gelo e centrifugadas a $10000 \mathrm{rpm}$ por 40 minutos a $4^{\circ} \mathrm{C}$. O sobrenadante foi coletado e acondicionado a $80^{\circ} \mathrm{C}$ até o momento da dosagem. 
A quantificação de proteína total foi realizada através do método de Badford $\left(\right.$ Bio Agency $\left.^{\circledR}\right)$ nos homogenatos dos órgãos.

\subsection{Quantificação TNF- $\alpha$, IL-6 e IL-10 por ELISA}

As dosagens dos mediadores inflamatórios foram realizadas pelo método de ELISA com os kits Duo Set (R\&D Systems ${ }^{\circledR}$ ) TNF- $\alpha$ (DY 410), IL-6 (DY406) e IL-10 (DY417).

Placas de 96 poços foram cobertas com $50 \mu$ de anticorpo primário diluídos em tampão fosfato (PBS) e incubadas por 18 horas a $4^{\circ} \mathrm{C}$. A placa foi lavada com PBS Tween $0,05 \%$ por 3 vezes. Em seguida foram acrescentados $200 \mu l /$ poço de PBS/BSA $1 \%$ para bloqueio dos sítios desocupados, por 1 hora a temperatura ambiente. Após a incubação as placas foram novamente lavadas. As amostras e as citocinas recombinantes em diluições de concentrações conhecidas foram plaqueadas em $100 \mu \mathrm{l} /$ poço, incubadas por 2 horas em $37^{\circ} \mathrm{C}$. Após a lavagem das placas, $50 \mu$ de anticorpo de detecção biotinilado para cada citocina foram acrescentados por 1 hora $37^{\circ} \mathrm{C}$. Após a lavagem, as placas foram incubadas com conjugado streptoavidina peroxidase diluída em PBS 1:200 (50 $\mu \mathrm{l})$ por 30 minutos a temperatura ambiente. As placas foram lavadas e incubadas com solução de tetrametilbenzidina durante 20 minutos. O bloqueio da reação ocorreu com o acréscimo de $25 \mathrm{ml} /$ poço de ácido sulfúrico $2 \mathrm{~N}$.

A densidade óptica das amostras foi determinada em leitor de ELISA (Genius - TECAN) com filtro de 450nm. As concentrações das citocinas (pg/mL) 
encontradas em pulmão e intestino foram normalizadas pelas concentrações de proteína total.

\subsection{Quantificação de Nitrito}

A produção de óxido nítrico foi determinada indiretamente pela medida de nitritos no soro dos camundongos e sobrenadante de cultura celular como descrito por Zhang [14]. Numa placa de 96 poços foram acrescentados $50 \mu \mathrm{l}$ de soro ou sobrenadante livre de células e $50 \mu \mathrm{l}$ reagente de Griess $(0,2 \% \quad \mathrm{~N}-1$ naftiletilenediamina, $2 \%$ sulfanilamida em $5 \%$ de ácido fosfórico). A absorbância foi determinada por leitor de ELISA (Genius - TECAN) com filtro de 550nm.

\section{Análise Estatística}

Para análise estatística de comparação de médias utilizou-se análise de variância (ANOVA). Teste 't' de student foi utilizado quando pertinente. Os dados estão apresentados como média \pm erro padrão da média e considerados significantes quando assumiram valores para $p<0,05$. O programa Instat- Versão 3.05 (GraphPad Software Incorporation) foi utilizado para análise dos dados e o teste de Log rank foi utilizado para a análise das curvas de sobrevidas. 


\section{Resultados}

\subsection{Cultura de célula B-1}

5.1.1. Citometria de fluxo: Pesquisa de célula B-1 em culturas de células peritoneais de camundongos Balb/c.

Células coletadas de sobrenadantes de 5 dias de culturas de células peritoneais de camundongos Balb/c foram analisadas por citometria de fluxo. $89,62 \%$ do total de células analisadas $\left(20 \times 10^{6}\right)$ apresentaram marcação de marcadores de superfície compatíveis com fenótipo de célula B-1b: CD11 b $\mathrm{CD}^{1}{ }^{+}, \mathrm{CD}^{2} 3^{-}$e CD5 . Os 10,38 \% restantes não apresentaram marcação.

\subsubsection{Detecção de IgM em cultura de célula B-1}

Não foi detectada IgM em culturas de células B-1 estimuladas ou não com LPS por $24 \mathrm{~h}$.

\subsubsection{Mediadores inflamatórios em cultura de Célula B-1 estimuladas} com LPS.

Nos sobrenadantes de células B-1 (Balb/c) após 24 horas de estímulo com LPS foram encontradas maiores concentrações de IL-10 (Figura-4a) do que o grupo sem estímulo. Não houve diferença na produção de TNF- $\alpha$ (Figura-4b), IL-6 (Figura-4c) e nitrito (Figura-4d) após tratamento com LPS. 


\subsection{Cultura de Macrófagos (RAW 264.7)}

Após 24 horas de estímulo com LPS foi observado aumento na quantificação de TNF- $\alpha$ (Figura-4b), IL-6 (Figura-4c), nitrito (Figura-4d) e não houve diferença na produção de IL-10 na cultura de macrófagos (Figura-4a).

\subsection{Coculturas}

\subsubsection{Coculturas de macrófago (RAW 264.7) e célula B-1 (Balb/c)}

Níveis de IL-10 (Figura-4a), TNF- $\alpha$ (Figura-4b) e IL-6 (Figura-4c), foram maiores no grupo que foi estimulado com LPS do que o grupo controle. A produção de nitrito não foi diferente nos grupos estudados (Figura-4d).

Ao compararmos as quantificações dos mediadores inflamatórios de cultura de macrófagos com as coculturas (macrófago + célula B-1 - Balb/c), encontramos diminuição na quantificação de TNF- $\alpha$, IL-6 e nitrito e aumento na quantificação de IL-10. Portanto, a presença da célula B-1 em cultura de macrófagos promoveu, tanto no grupo controle quanto no grupo estimulado com LPS por $24 \mathrm{~h}$, diminuição do perfil inflamatório e aumento do perfil antiinflamatório nas culturas de macrófagos (Figura 4). 

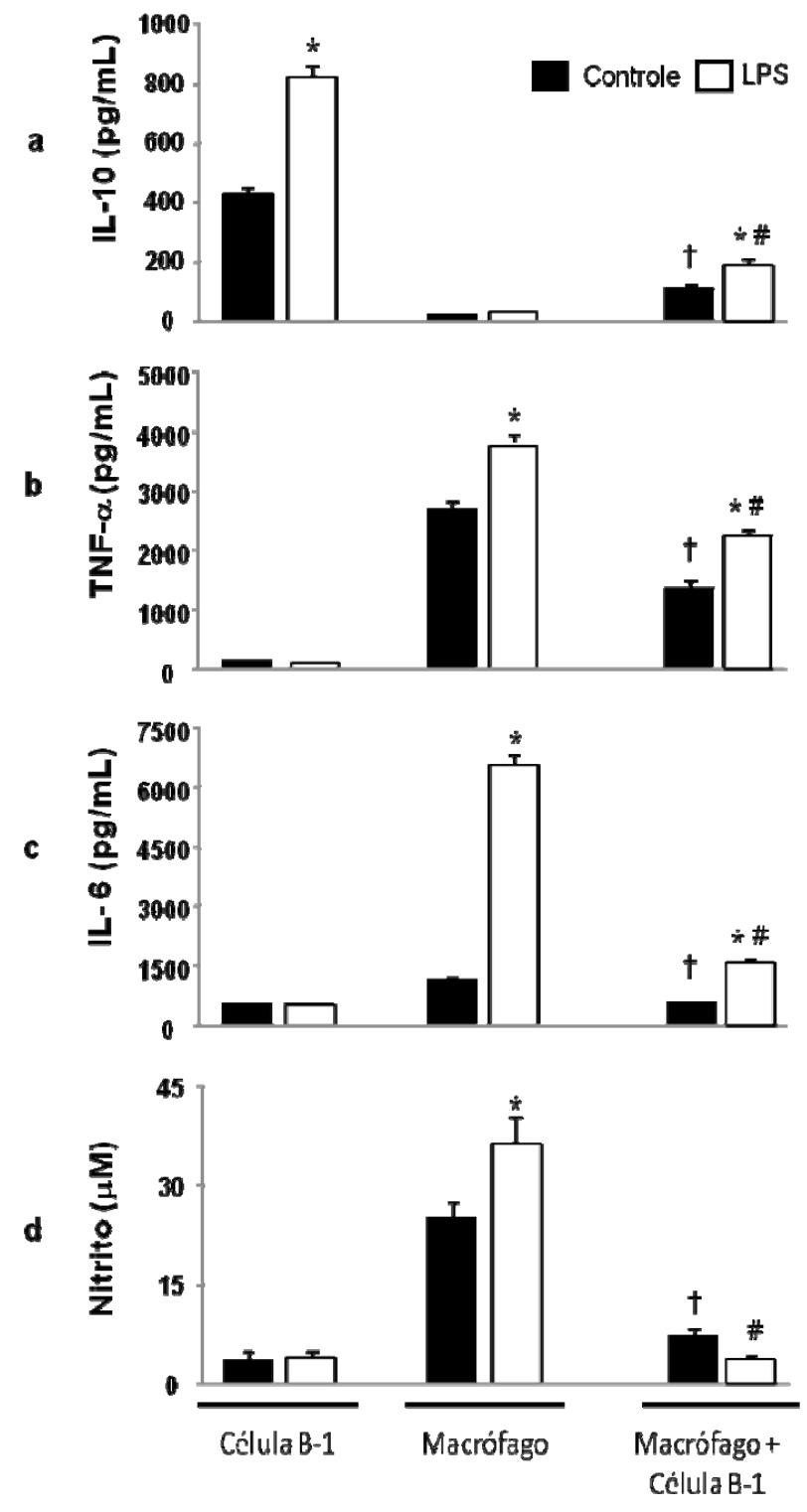

Figura 4- Concentrações de IL-10 (a), TNF- $\alpha$ (b), IL-6 (c) e Nitrito (d) nos sobrenadantes de culturas de células B-1(Balb/c WT), macrófagos RAW 264.7 e coculturas (macrófagos RAW 264.7 + células B-1 (Balb/c WT) após 24 horas de estímulo com LPS a $10 \mu \mathrm{g} / \mathrm{mL}$. Valores expressos em média \pm EPM de três experimentos independentes * $\mathrm{p}<0,05$ quando comparado com controle do mesmo grupo; \# $p<0,05$ quando comparado com os demais grupos estimulados com LPS e $\dagger<0,05$ quando comparado com os demais grupos controle. 
Com estes resultados, decidimos então estudar o perfil inflamatório de macrófagos em cocultura com célula B-1 desprovidas de IL-10 provenientes de camundongos C57BL/6 IL-10\%.

\subsubsection{Coculturas de Macrófagos (RAW 264.7) e células B-1 (C57IL-}

$10 \%$

O estímulo com LPS aumenta a quantificação de IL-6 e nitrito em macrófagos na presença de célula B-1 (C57BL/6) e em relação à produção de TNF- $\alpha$ não houve diferença estatística (Figura-5).

Em coculturas de macrófagos + células B-1 provenientes de camundongos C57BL/6 IL-10 \% houve aumento da produção de mediadores inflamatórios TNF$\alpha$, IL-6 e nitrito (Figura-5).

Além disso, a presença de células B-1 (IL-10 \%) em cultura de macrófagos potencia a produção de mediadores proinflamatórios (TNF- $\alpha$, IL-6 e nitrito) pelos macrófagos em cultura após a exposição ao LPS (Figura-5). 

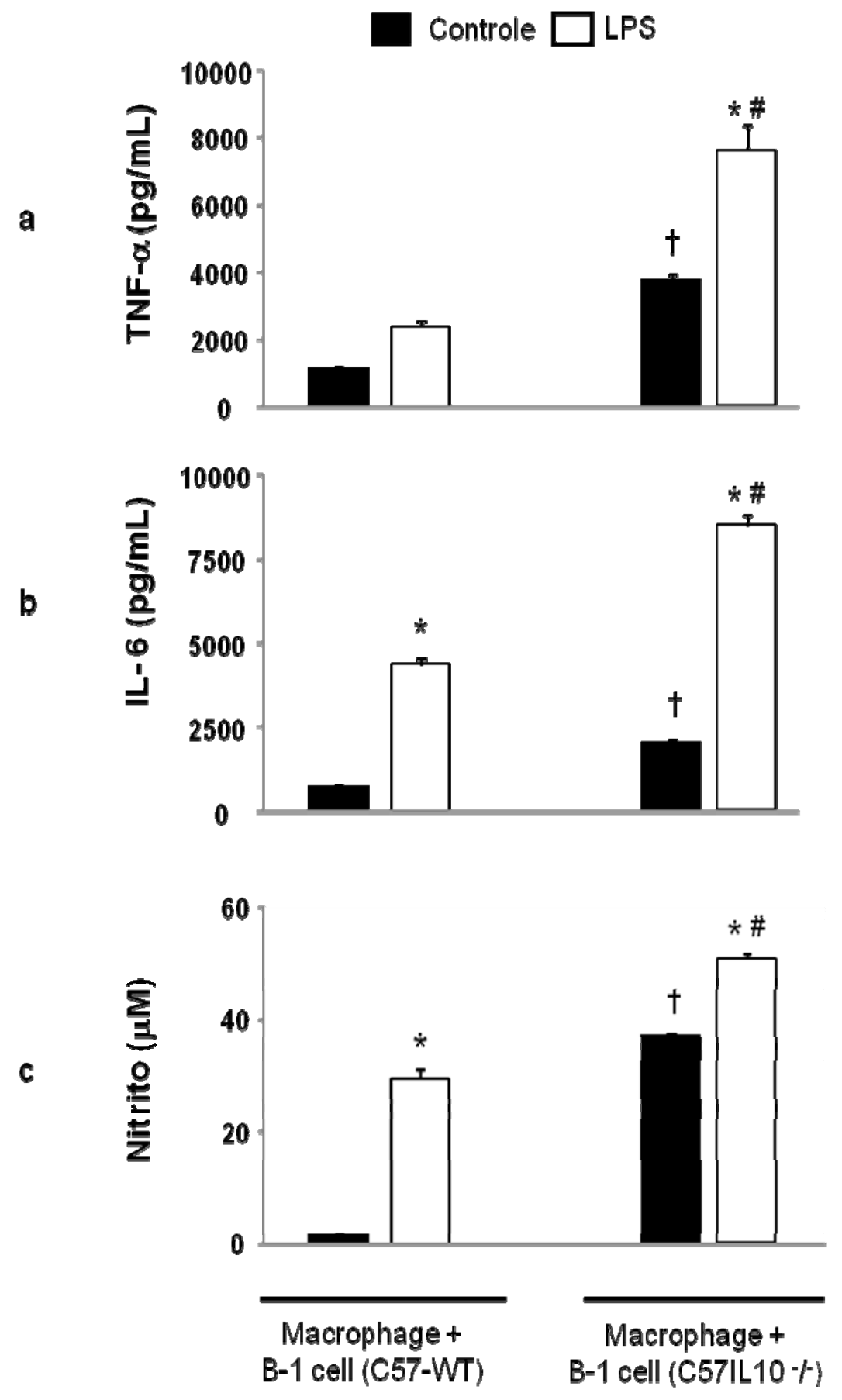

Figura 5- Concentrações de TNF- $\alpha$ (a), IL-6 (b) e Nitrito (c) em sobrenadantes de coculturas (macrófagos RAW 264.7) + células B-1 (C57WT ou C57IL-10\%) após 24 horas de estímulo com LPS a $10 \mu \mathrm{g} / \mathrm{mL}$. Valores expressos em média \pm EPM de dois experimentos independentes. * $p<0,05$ quando comparado com controle do mesmo grupo; \# $p<0,05$ quando comparado com os demais grupos estimulados com LPS e $\dagger<0,05$ quando comparado os demais com grupos controle. 
Com os resultados das coculturas mostrando um papel modulador via IL-10 pela célula B-1 na resposta inflamatória ao LPS, fizemos um experimento onde doses crescentes de rIL-10 foram acrescentadas às culturas de macrófagos (RAW264.7) que demonstrou que à medida que aumentamos a dose de rIL-10 na presença de LPS, as concentrações de TNF- $\alpha$ (Figuras 6) e IL-6 diminuem (Figuras 7) e nitrito aumentam (Figura 8).

Os resultados obtidos com o estudo in vitro, nos levaram a estudar o perfil inflamatório em animais Balb/Xid (imunodeficientes em célula B-1) e Balb/c após indução de endotoxemia por injeção de LPS. Antes deste estudo, fizemos uma pesquisa de célula B-1 em células peritoneais das duas linhagens e também estudamos o comportamento de células peritoneais aderentes destes animais quando estimulados com LPS. 


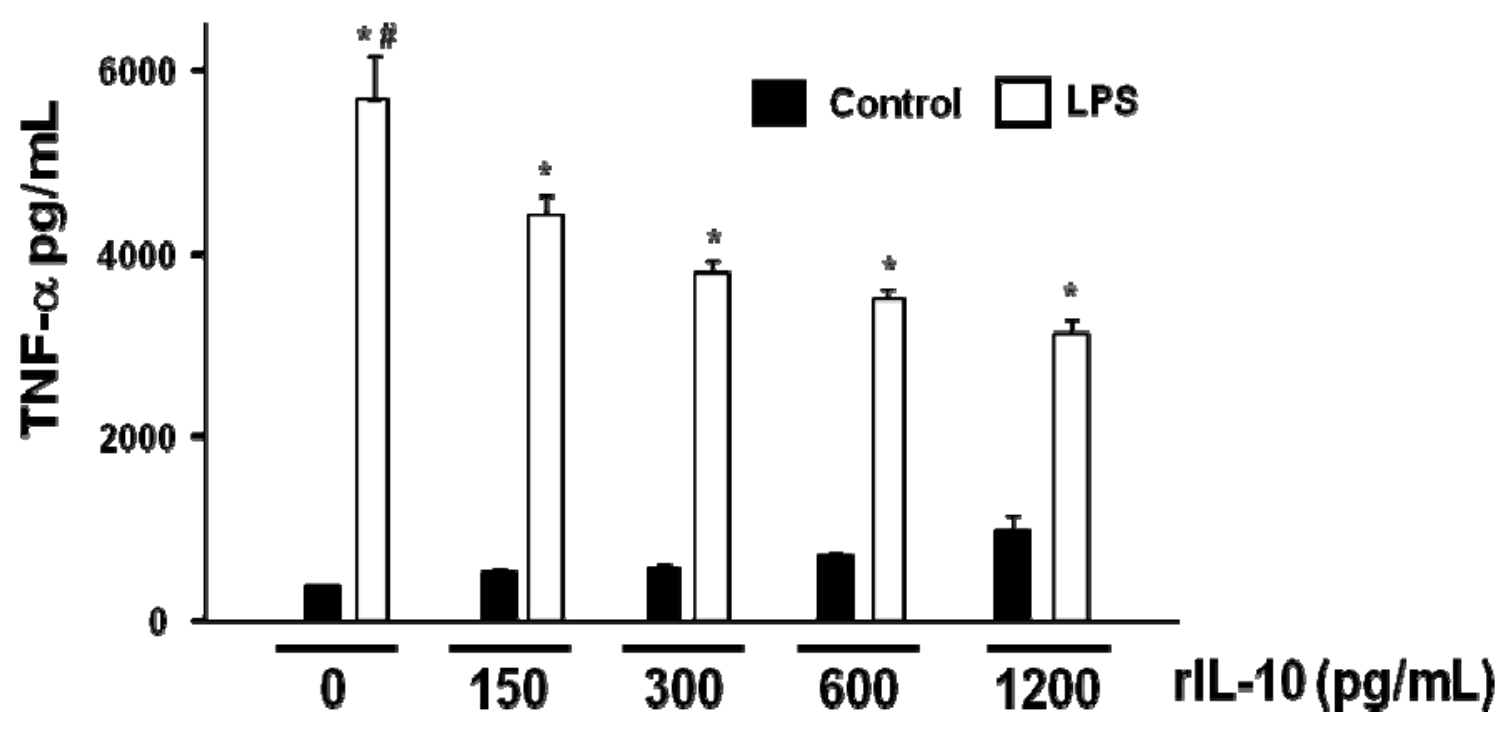

Figura 6- Concentrações de TNF- $\alpha$ em sobrenadantes de cultura de macrófagos (RAW 264.7) após 24 horas de estímulo com LPS a $10 \mu \mathrm{g} / \mathrm{mL}$ e doses crescentes de rlL-10. Valores expressos em média \pm EPM de dois experimentos independentes. * $p<0,05$ quando comparado respectivo grupo controle; \# $p<0,05$ quando comparado com os demais grupos estimulados com LPS. 


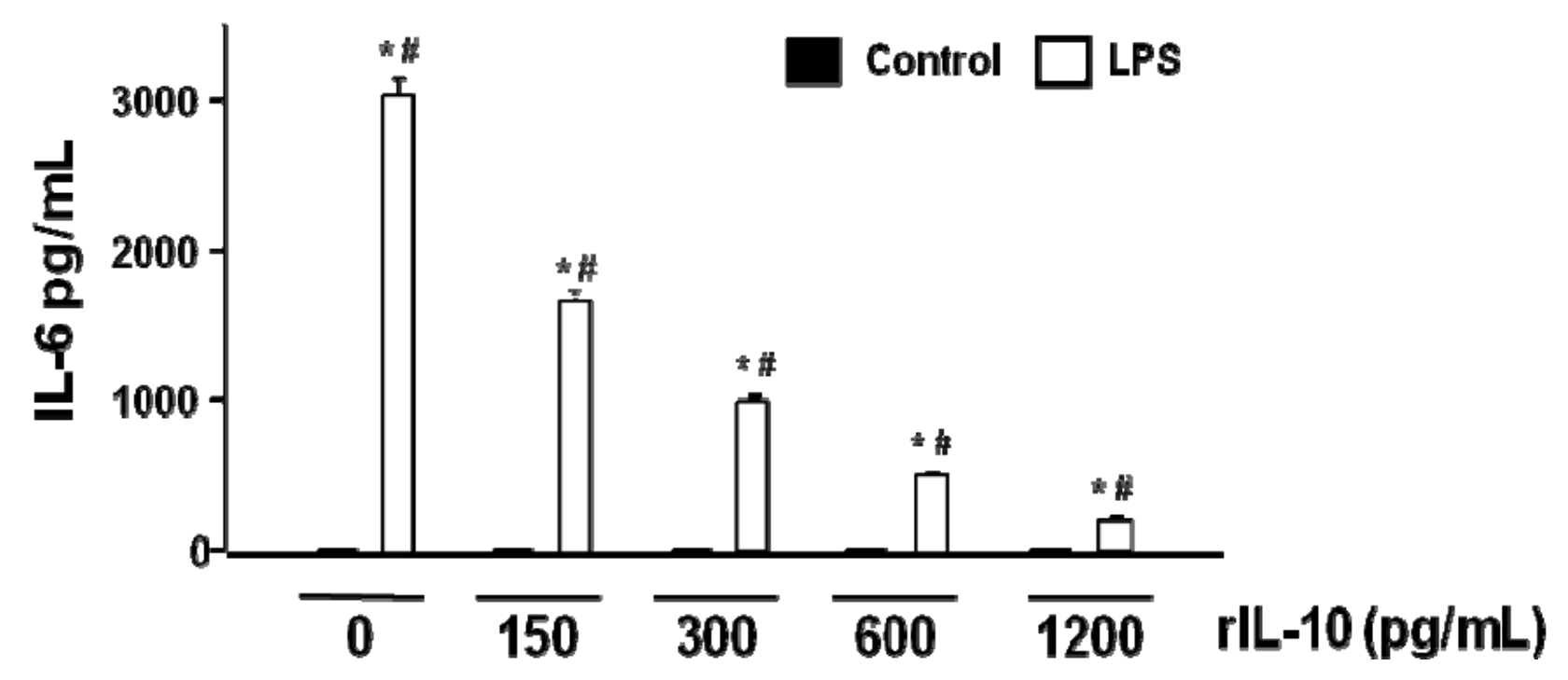

Figura 7- Concentrações de IL-6 em sobrenadantes de cultura de macrófagos (RAW 264.7) após 24 horas de estímulo com LPS a $10 \mu \mathrm{g} / \mathrm{mL}$ e doses crescentes de rIL-10. Valores expressos em média \pm EPM de dois experimentos independentes. ${ }^{*} p<0,05$ quando comparado respectivo grupo controle; $\# p<0,05$ quando comparado com os demais grupos estimulados com LPS. 


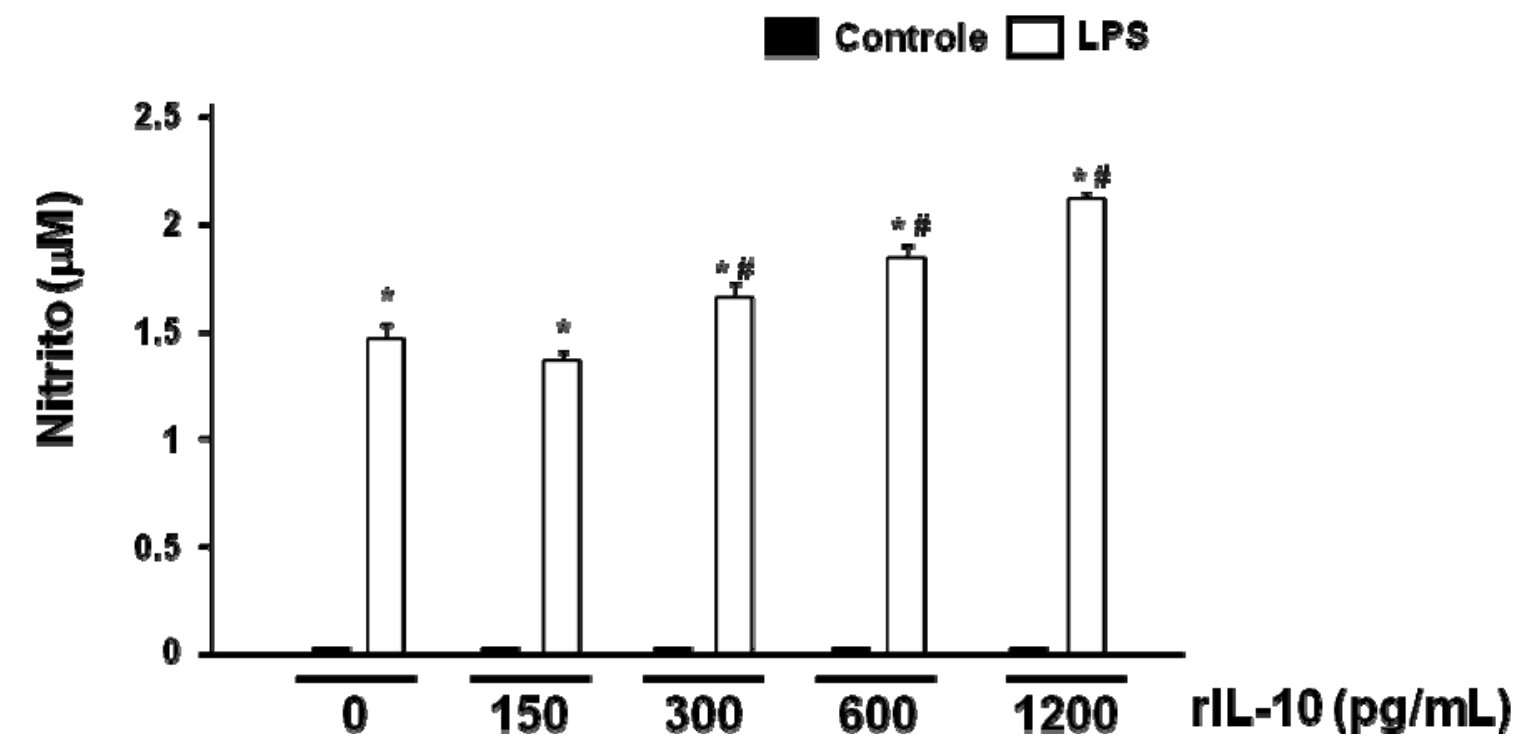

Figura 8- Concentrações de Nitrito em sobrenadantes de cultura de macrófagos (RAW 264.7) após 24 horas de estímulo com LPS a $10 \mu \mathrm{g} / \mathrm{mL}$ e doses crescentes de rlL-10. Valores expressos em média \pm EPM de dois experimentos independentes. ${ }^{*} p<0,05$ quando comparado respectivo grupo controle; $\# p<0,05$ quando comparado com os demais grupos estimulados com LPS. 
5.4. Pesquisa de células B-1: Citometria de fluxo das células peritoneais de camundongos Balb/c e Balb/Xid

Através da análise das células peritoneais dos camundongos, encontramos 45\% de células B-1 em Balb/c e 0,19\% em Balb/Xid (Figura 9).

\subsection{Perfil inflamatório de células peritoneais em cultura de Balb/c e Balb/Xid estimuladas com LPS}

Após 24 horas de estímulo com LPS, foi observado aumento da produção de TNF- $\alpha$, IL-6, IL-10 e nitrito em sobrenadante de células peritoneais de camundongos da linhagem Balb/Xid, enquanto que na linhagem Balb/c foi observado aumento na produção de TNF- $\alpha$ e IL-6.

Comparando os resultados obtidos entre as duas linhagens, foi observado maior quantificação de TNF- $\alpha$, IL-6 e nitrito no sobrenadante de cultura de células peritoneais de animais da linhagem Balb/Xid enquanto que na quantificação de IL10 não foi observada diferença (Figura 10). 

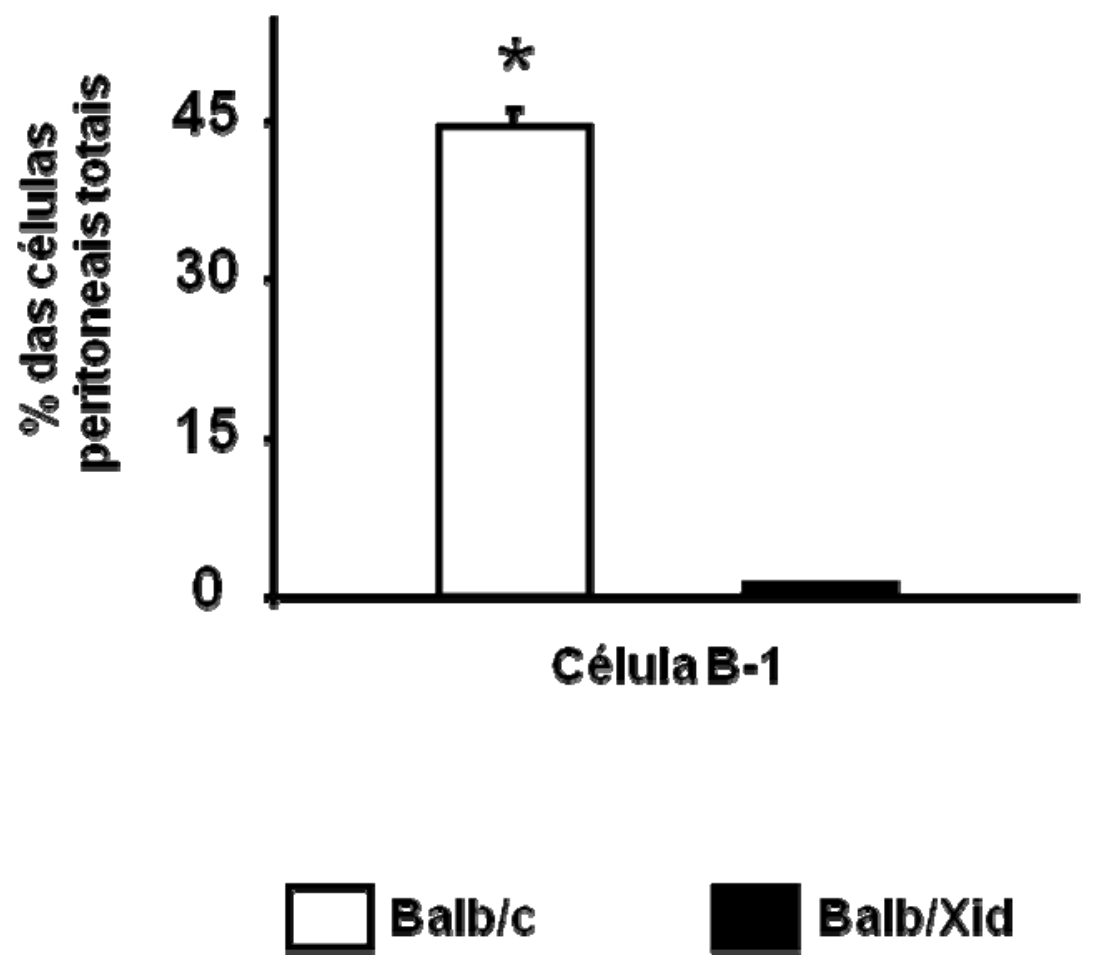

Figura 9- Pesquisa de células $B-1\left(C D 11 b^{+}, C D 19^{+}, C D^{-}\right.$e CD23- em peritônios de camundongos Balb/c $(n=3)$ e Balb/Xid $(n=3)$ por citometria de fluxo. Os resultados são expressos em porcentagem (\%) da média de 3 animais por grupo. 
(a)
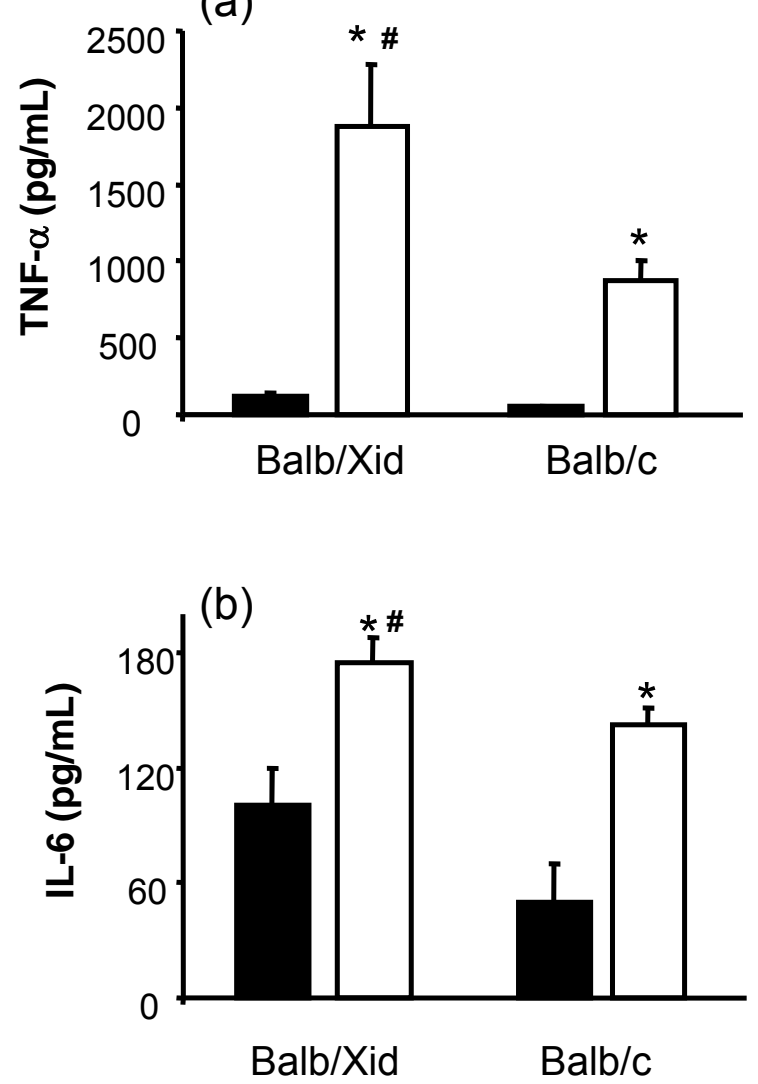
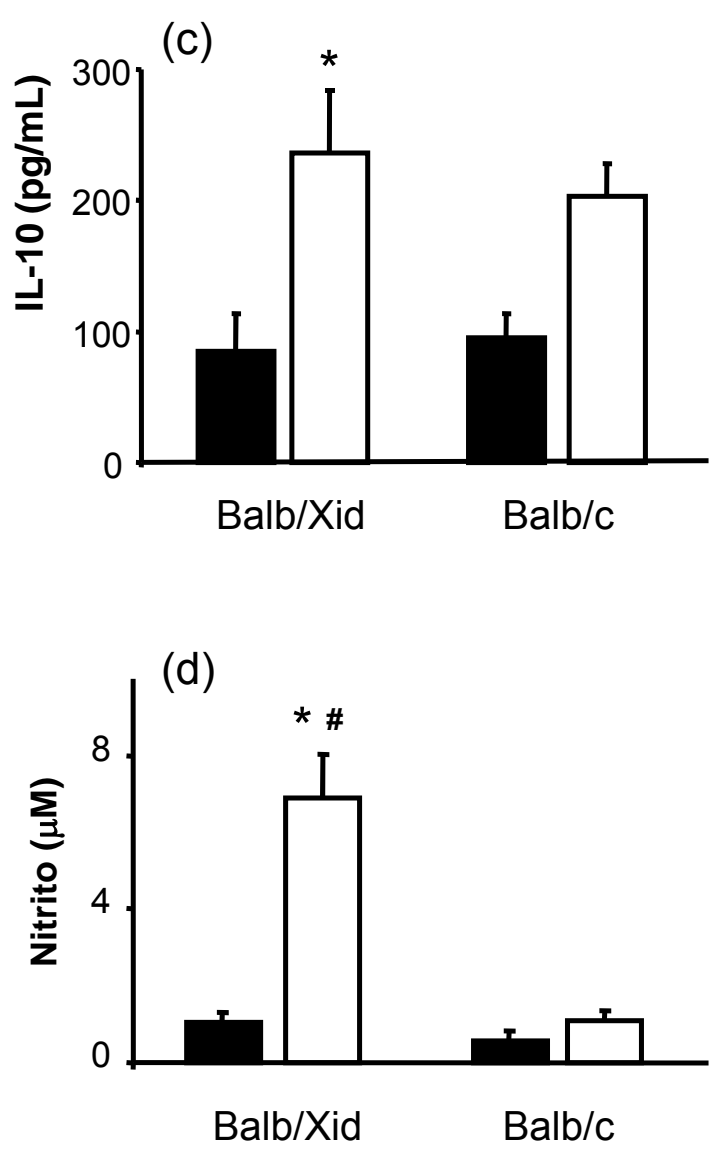

$\square$ Controle $\square$ LPS

Figura 10- Concentrações de TNF- $\alpha$ (a), IL-6 (b), IL-10 (c) e Nitrito (d) nos sobrenadantes de cultura de células peritoneais de camundongos Balb/c e Balb/Xid após 24 horas de estímulo com LPS a $10 \mu \mathrm{g} / \mathrm{mL}$. Valores expressos em média \pm EPM de três experimentos independentes * $p<0,05$ quando comparado com grupo controle do mesmo grupo de animais; \# $p<0,05$ quando comparado com Balb/c LPS 24 horas. 


\subsection{Modelo de Endotoxemia}

\subsubsection{Curva de sobrevida}

Os dados obtidos demonstram maior sensibilidade da linhagem Balb/Xid aos efeitos do LPS. Após 24 horas do estímulo, somente 40\% dos animais desta linhagem sobreviveu enquanto que na linhagem Balb/c não foi observado nenhum óbito (Figura-11).

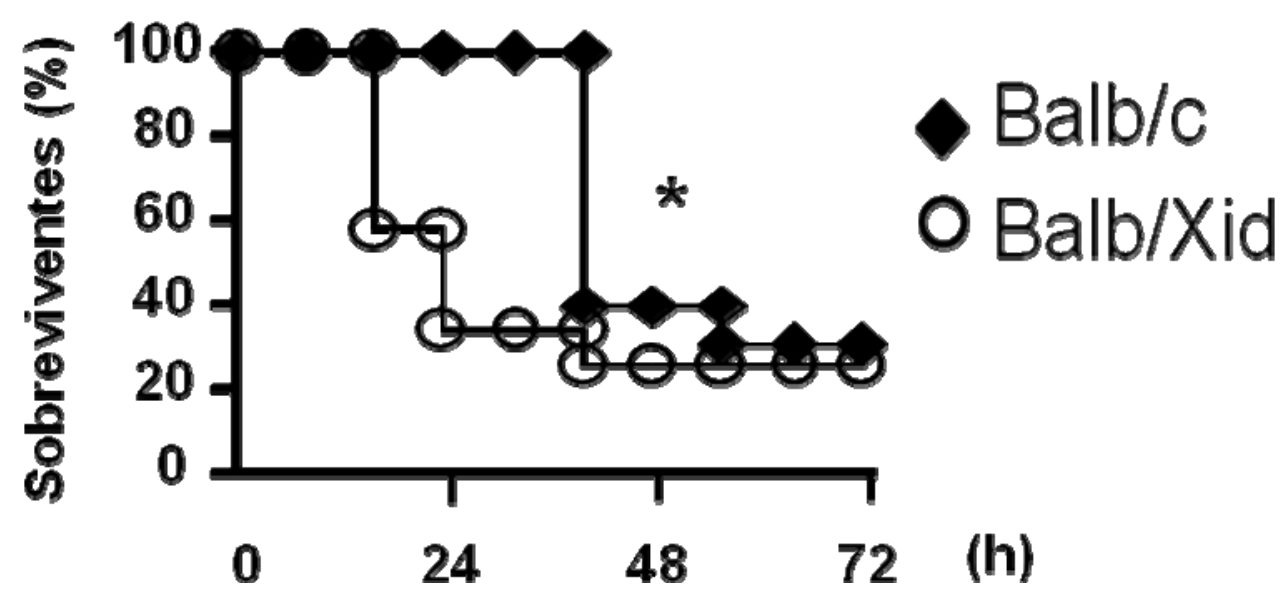

Figura 11- Sobrevida dos animais das linhagens Balb/c e Balb/Xid submetidos à injeção de LPS $15 \mathrm{mg} / \mathrm{kg}$. A sobrevivência foi avaliada a cada 12 horas por 72 horas. Os resultados são expressos em \% de sobrevivência e os dados apresentados são de 10 animais por linhagem. * $p<0,05$ quando comparado com Balb/Xid (log rank). 


\subsubsection{Produção de mediadores inflamatórios em Balb/Xid e Balb/c} após injeção de LPS.

Como intuito de verificar possíveis alterações no perfil inflamatório que podem estar relacionadas com a maior mortalidade observada na linhagem Balb/Xid, nós estudamos o perfil da produção de mediadores inflamatórios ao longo do tempo em soro, pulmão e intestino nas duas linhagens após endotoxemia induzida por LPS.

Após a injeção de LPS, foram detectadas no soro, pulmão e intestino dos animais da linhagem Balb/Xid maiores concentrações IL-6 e TNF- $\alpha$ enquanto que a produção de IL-10 foi menor quando comparado com Balb/c.

No soro dos animais da linhagem Balb/Xid foram detectadas maiores concentrações de TNF- $\alpha(1,5 h)$ e IL-6 (1,5, 4 e $6 h)$ enquanto que a produção de IL-10 foi menor após 1,5h da injeção de LPS (Figura 12).

O estudo realizado no homogenato de pulmão dos animais após a injeção de LPS mostra concentrações de TNF- $\alpha$ (4h) e IL-6 (4 e 6h) elevadas e menores níveis de IL-10 na linhagem Balb/Xid (Figura 13).

As quantificações de TNF- $\alpha$ e IL-6 em homogenato de intestino dos animais da linhagem Balb/Xid foram maiores após 1,5 (TNF- $\alpha$ ), 4 e $6 \mathrm{~h}$ (IL-6). A produção de IL-10 foi menor após 1,5 e 6h em relação à linhagem Balb/c (Figura 14). 


\section{Soro}

a)

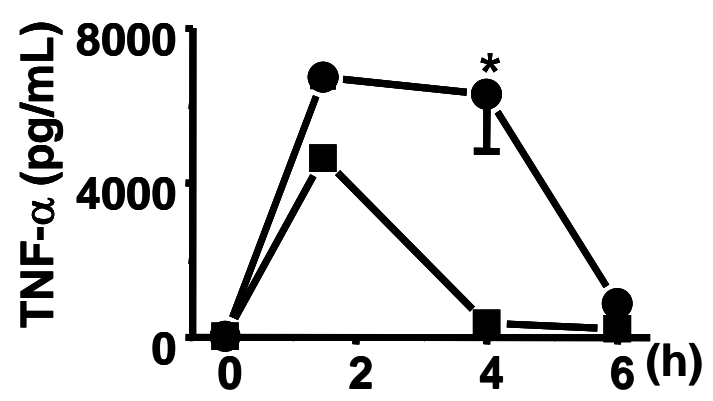

b)

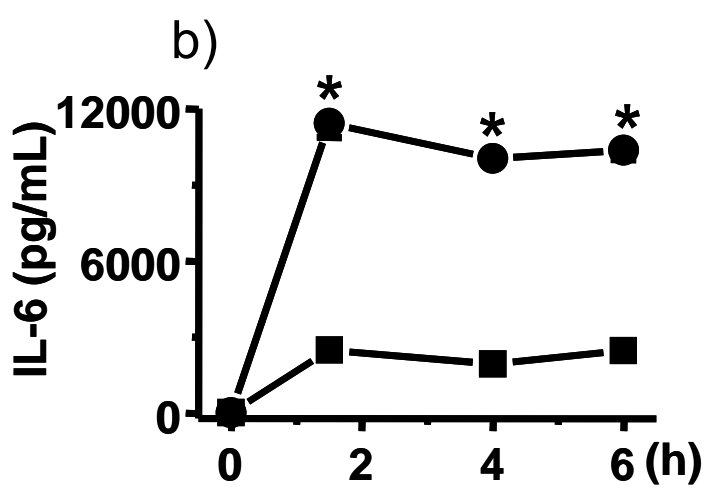

c)

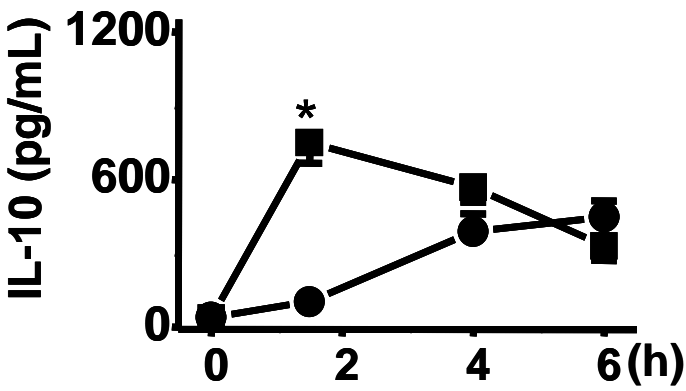

$\rightarrow$ Balb/c

$\rightarrow-$ Balb/Xid

Figura 12- Perfil inflamatório entre linhagens Balb/Xid e Balb/c após a indução da endotoxemia por LPS. Concentrações de TNF- $\alpha$ (a), IL-6 (b) e IL-10 (c) em soro dos animais após 1,5 $(n=6), 4(n=6)$ e $6(n=6)$ horas da injeção de LPS. Valores expressos em média \pm EPM. ${ }^{*} p<0,05$ quando comparado Balb/Xid e Balb/c no mesmo período de estudo. 


\section{Pulmão}

a)

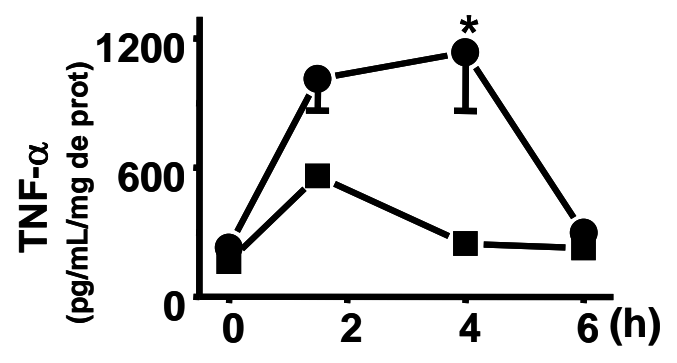

b)

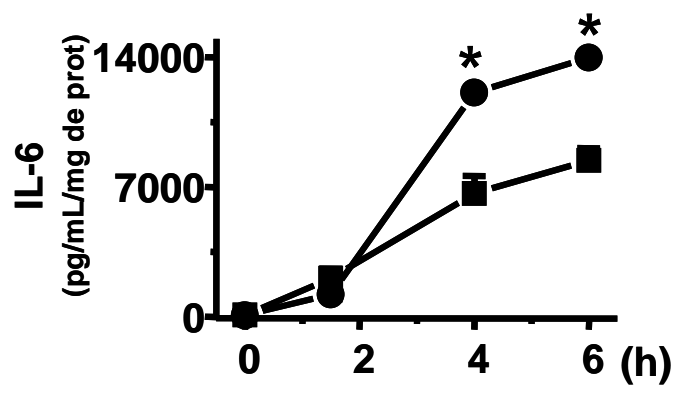

c)

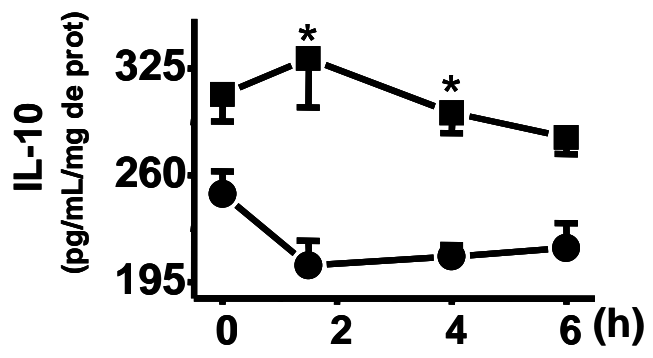

Figura 13- Perfil inflamatório entre linhagens Balb/Xid e Balb/c após a indução da endotoxemia por LPS. Concentrações de TNF- $\alpha$ (a), IL-6 (b) e IL-10 (c) em pulmão dos animais após 1,5 $(n=6), 4(n=6)$ e $6(n=6)$ horas da injeção de LPS. Valores expressos em média \pm EPM. * $p<0,05$ quando comparado Balb/Xid e Balb/c no mesmo período de estudo. 


\section{Intestino}

a)

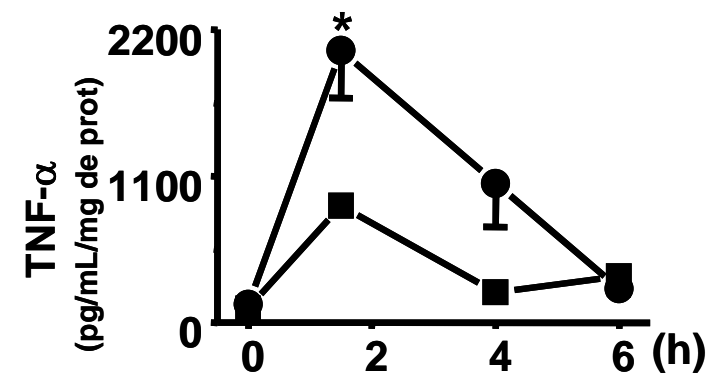

b)

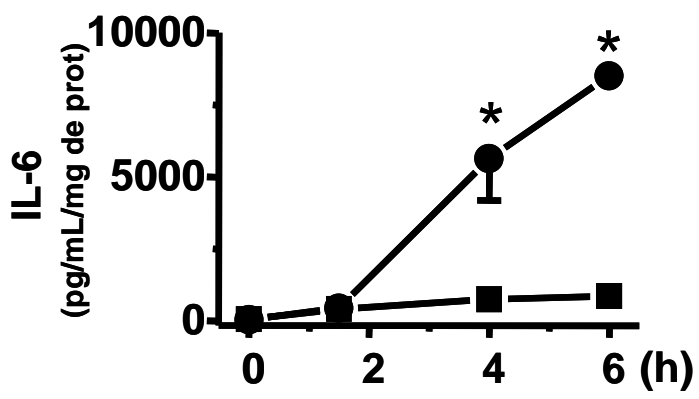

c)

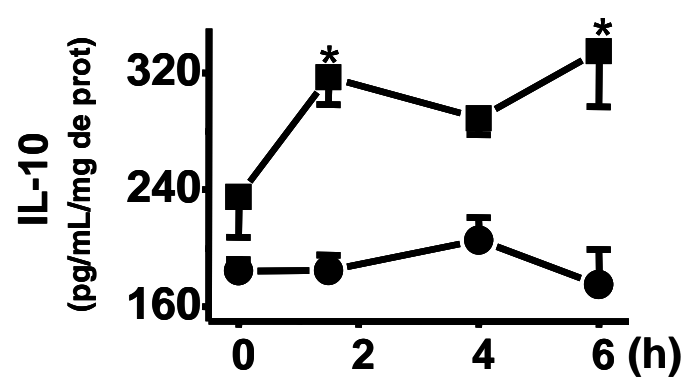

$\rightarrow$ Balb/c

$\rightarrow$ Balb/Xid

Figura 14- Perfil inflamatório entre linhagens Balb/Xid e Balb/c após a indução da endotoxemia por LPS. Concentrações de TNF- $\alpha$ (a), IL-6 (b) e IL-10 (c) em intestino dos animais após 1,5 $(n=6), 4(n=6)$ e $6(n=6)$ horas da injeção de LPS. Valores expressos em média \pm EPM. ${ }^{*} p<0,05$ quando comparado Balb/Xid e Balb/c no mesmo período de estudo. 
5.6.3. Perfil da produção de Nitrito em soro de animais Balb/c e Balb Xid após injeção de LPS

Os dados obtidos na quantificação de nitrito em soro de animais após a injeção de LPS não apresentaram diferença estatística nos períodos estudados (Figura 15).

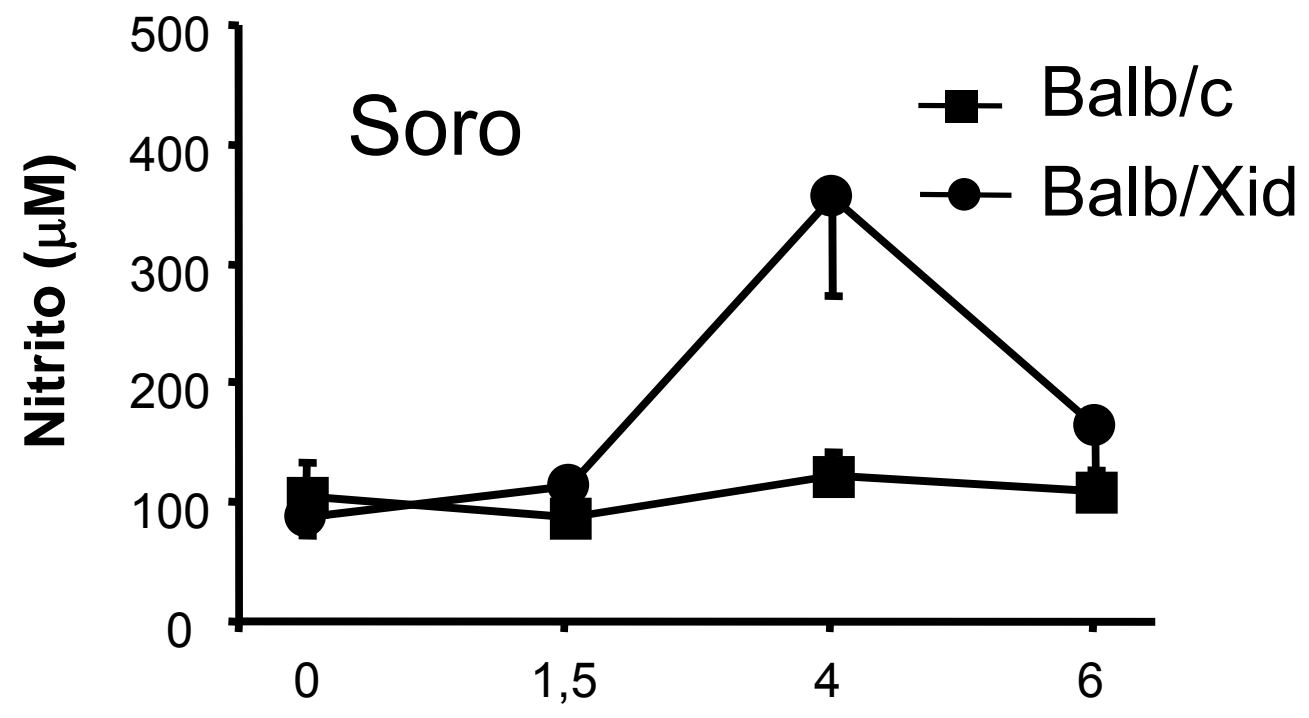

Figura 15- Concentrações de Nitrito no soro, de animais submetidos à injeção de LPS após 1,5, 4 e 6 horas em Balb/c $(n n=6)$ e Balb/Xid $(\bullet n=6)$. Valores expressos em média \pm EPM. Não houve diferença estatística entre as linhagens nos períodos estudados. 


\subsection{Inoculação de Célula B-1 (Balb/c) em peritônio de Balb/Xid}

5.7.1 Detecção de células B-1: Citometria de fluxo das células peritoneais de camundongos Balb/Xid reconstituídos com células B-1 (Balb/c)

A análise por citometria de fluxo mostra que os animais que receberam células $\mathrm{B} 1$ a uma concentração de $1 \times 10^{6} \mathrm{céls} / \mathrm{mL}$, apresentam maior quantidade destas células no peritônio após 7 dias da inoculação (Figura 16).

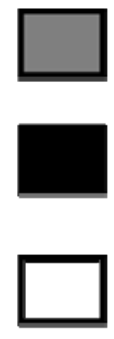

\section{Balb/Xid}

Balb/XId+célula B-1 ( $5 \times 10^{5}$ céls. $\left./ \mathrm{mL}\right)$

\section{Balb/Xid+célula B-1 ( $\left.1 \times 10^{6} \mathrm{cé} / \mathrm{s} . \mathrm{mL}\right)$}

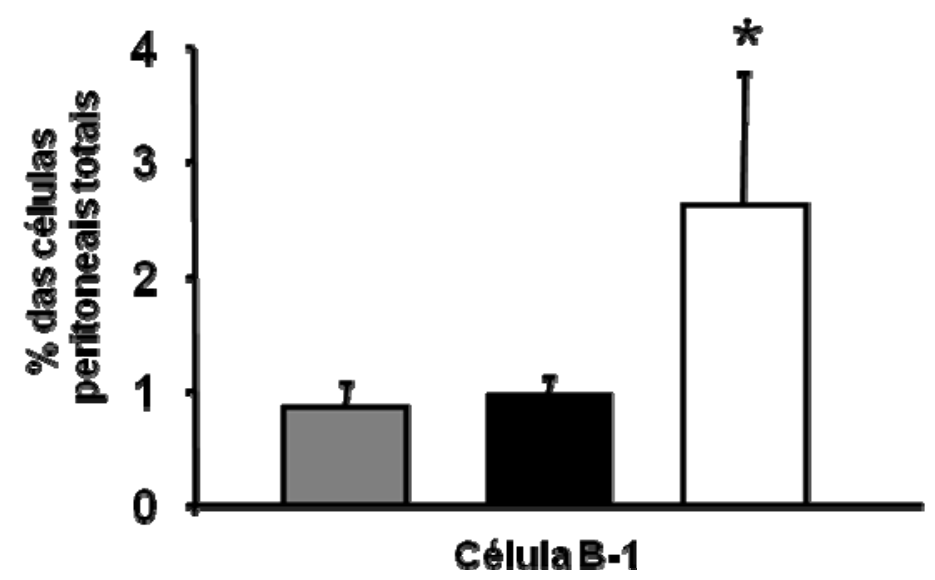

Figura 16 - Pesquisa de células B-1 (CD11 $\mathrm{b}^{+}, \mathrm{CD}_{19}{ }^{+}, \mathrm{CD}^{-}$e CD23-) em peritônios de camundongos Balb/Xid $(n=3)$, Balb/Xid reconstituídos com célula $B-1$ com $5 \times 10^{5}$ céls. $/ \mathrm{mL}(\mathrm{n}=3)$ e $1 \times 10^{6}$ céls. $/ \mathrm{mL}(\mathrm{n}=3)$ por citometria de fluxo após 7 dias da inoculação. * $p<0,05$ quando comparado com os outros grupos. 


\subsubsection{Sobrevida dos animais Balb/Xid e Balb/Xid reconstituídos com célula}

\section{B-1 (Balb/c) após injeção de LPS}

Uma curva de sobrevida foi realizada onde Balb/Xid reconstituídos com célula B-1 por 7 dias $\left(1 \times 10^{6}\right.$ céls $\left./ \mathrm{mL} n=6\right)$ e animais Balb/Xid controles $(n=6)$ foram submetidos à injeção de LPS (15mg/kg). A figura 17 mostra que os animais inoculados com célula B-1 foram menos sensíveis aos efeitos do LPS morrendo após 24hs enquanto que os Balb/Xid começaram a morrer 16hs após o estímulo.

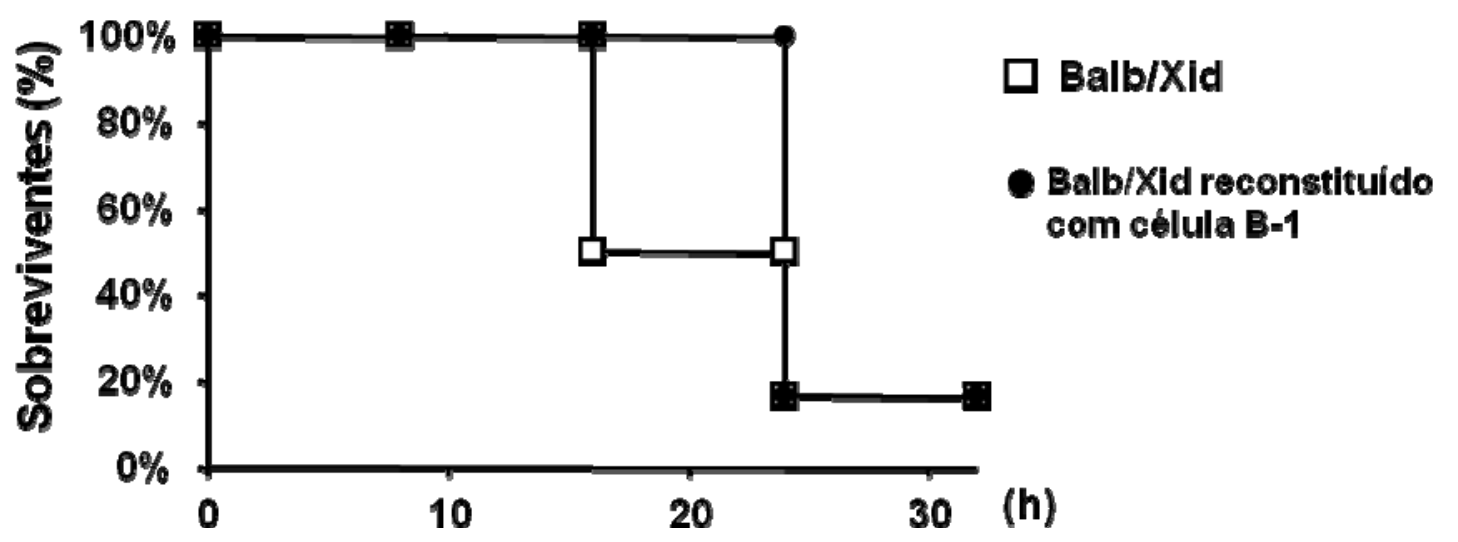

Figura 17- Sobrevida dos animais das linhagens Balb/Xid e Balb/Xid inoculados com células B-1 (WT) submetidos à injeção de LPS $15 \mathrm{mg} / \mathrm{kg}$. Os resultados são expressos como \% de sobrevivência e os dados apresentados são de 6 animais de cada grupo. Não houve diferença na taxa de sobrevida dos animais. 


\section{Discussão}

A sepse é uma doença grave caracterizada por resposta inflamatória sistêmica e é uma das maiores causas de morte em UTI não coronariana. As células do sistema imunológico participam ativamente do processo inflamatório, liberando vários mediadores inflamatórios com o intuito de eliminar o agente causador da infecção. Isto que pode tornar o processo exacerbado, agravando a doença e levando assim, a disfunção de órgãos e à morte. Por isso, o conhecimento das funções e interações celulares nestas condições é de extrema importância.

Dentre as células do sistema imunológico que participam da resposta inflamatória, os linfócitos B exercem várias funções regulatórias, dentre elas a secreção de imunoglobulinas, produção de citocinas, apresentação de antígenos, e interação com vários tipos celulares [45].

A resposta inflamatória exacerbada causa dano celular podendo culminar na morte. Todas as células podem ser lesadas neste processo, e dentre estas os linfócitos, que na presença de TNF- $\alpha$ e radicais livres entram em apoptose. A perda de massa linfocitária acarreta num estado de imunossupressão, e consequentemente em dificuldade do hospedeiro em manter a homeostase e eliminar microorganismos invasores [51].

As células B-1, principal fonte de anticorpos naturais e IL-10 em peritônio de camundongos, foram encontradas também em cavidade peritoneal de humanos [52], onde participa de processos autoimunes como lúpus, artrite reumatóide [53] e endometriose [54]. Além disso, estas células apresentam capacidade de 
autorenovação tanto in vivo quanto in vitro. Nosso estudo mostrou que a quantidade de célula B-1 (89,62 \%) presente na cultura de 5 dias do lavado peritoneal é semelhante aos encontrados por outros autores [39, 41, 55, 56]. Estas células apresentaram $\mathrm{CD} 11 \mathrm{~b}^{+}, \mathrm{CD} 19^{+}$e $\mathrm{CD} 5$, caracterizando o fenótipo de célula peritoneal B-1b.

O LPS tem sido usado como modelo experimental por desencadear a resposta inflamatória mimetizando os eventos da sepse [14].

Em culturas de células B-1 estimuladas com LPS não encontramos alteração nas quantificações de TNF- $\alpha$ (Figura 4b), IL-6 (Figura 4c) e o NO (Figura 4d). Por outro lado, encontramos aumento significativo na quantificação de IL-10 (Figura 4a). Este padrão de mediadores indica um potencial de ação antiinflamatório pela célula B-1. O oposto ocorre com o perfil de mediadores inflamatórios produzidos pelos macrófagos já que as células, após o estímulo com LPS, produziram maiores concentrações de TNF- $\alpha$ (Figura 4b), IL-6 (Figura 4c) e NO (Figura4d), enquanto não foi detectada diferença significativa na produção de IL-10 (Figura 4a) nestas culturas.

Ao estudarmos o macrófago RAW em cocultura com a célula B-1, observamos respostas diferentes quando comparamos com culturas isoladas de célula B-1 ou macrófagos estimulados ou não com LPS. Em cocultura o estímulo com LPS aumenta as quantificações de IL-10 (Figura 4a), TNF- $\alpha$ (Figura 4b) e IL-6 (Figura 4c) e nenhuma alteração foi observada na produção de nitrito (Figura 4d). É importante observar o papel modulador da célula B-1 na resposta inflamatória, onde, os mediadores inflamatórios estudados em cocultura apresentaram valores 
intermediários entre as culturas isoladas de macrófagos e culturas isoladas de células B-1. Quando comparamos os valores encontrados em coculturas com cultura de macrófagos isolados, observamos que a presença da célula B-1 nas coculturas de macrófagos promoveu diminuição das quantificações de TNF$\alpha$ (Figura 4b), IL-6 (Figura4c) e NO (Figura 4d), enquanto maiores concentrações de IL-10 foram detectadas.

Os resultados obtidos com as coculturas indicam que a célula B-1 em cultura com macrófagos tem ação antiinflamatória, possivelmente, em função do aumento de IL-10. Com o objetivo de comprovar a dependência da IL-10 como uma via utilizada pela célula B-1 nesta sinalização intercelular, realizamos dois novos grupos experimentais. No primeiro experimento utilizamos célula B-1 de animais C57BL/6 IL10 \% ou célula B-1 de C57BL/6 em cocultura com macrófago de linhagem (RAW 264.7). Os valores basais para TNF- $\alpha$ (Figura 5a), IL-6 (Figura 5b) e nitrito (Figura 5c) da cocultura de macrófagos (RAW 264.7) e célula B-1 de C57BL/6 IL10 \% são maiores quando comparamos com cocultura de macrófagos (RAW 264.7) e célula B-1 de C57BL/6, mostrando que a ação moduladora antiinflamatória tem a participação da IL-10.

No segundo experimento realizamos quantificação de TNF- $\alpha$, IL-6 e nitrito com a adição de doses crescentes de IL-10 recombinante (rIL-10) em cultura de macrófagos (RAW 264.7) estimuladas com LPS. À medida que as concentrações de rlL-10 aumentaram, os valores de TNF- $\alpha$ (Figura 6) e IL-6 (Figura 7) diminuíram, porém as concentrações de nitrito aumentaram (Figura 8). A diminuição de TNF- $\alpha$, IL6 e IFN- $\gamma$ está descrita na literatura em experimentos com 
macrófagos de linhagem após o estímulo com LPS e rlL-10 [57]. Em relação ao aumento significativo da produção de NO, dados semelhantes aos nossos foram encontrados em experimentos com cultura de macrófagos de linhagem (J774) por Jacobs e colaboradores [58]. Porém, outros trabalhos mostram que a produção de óxido nítrico diminui após tratamento com rlL-10 em cultura de monócitos e macrófagos $[59,60]$ mantendo este assunto controverso na literatura.

Popi e colaboradores [41] demonstram que a IL-10 produzida pelas células B-1 é responsável pela modulação da atividade fagocítica de macrófagos ao zimosam. A IL-10 é uma potente citocina antiinflamatória por diminuir a produção de mediadores proinflamatórios, inibir a proliferação de células T [61], estimular a secreção de imunoglobulinas [29] e proteger os animais em modelos de endotoxemia por LPS $[62,63]$. Em ensaios in vitro a IL-10 está diretamente relacionada à diminuição de síntese de citocinas Th1 como TNF- $\alpha$ e IL-6 tanto em macrófagos de linhagem quanto em células peritoneais de camundongos [57]. A inibição da ativação de proteínas como $N F \kappa \beta$, p38 e MyD88 devem estar envolvidos neste mecanismo [64].

O fato de a rlL-10 aumentar a produção de NO na presença de LPS, evidencia que o efeito desta interleucina não é de uma redução generalizada da resposta macrofágica. Possivelmente a presença de rlL-10 em culturas de macrófagos gera mudança no padrão de resposta, isto é aumenta a capacidade de destruição do invasor e também estimula a secreção de imunoglobulina pelo linfócito B. 
Nossos resultados dos estudos in vitro confirmaram que a sinalização utilizada pela célula B-1 na resposta inflamatória ao LPS, principalmente pela célula $B-1 b$ é realizada através da secreção de IL-10. As características fenotípicas e funcionais das células B-1 nos levam a acreditar que a via da IL-10 não seja a única via utilizada para a modulação da resposta inflamatória.

Além de fonte de IL-10, outra característica marcante da célula B-1, principalmente $\mathrm{B}-1 \mathrm{a}\left(\mathrm{CD}^{+}\right)$, é a produção de anticorpos naturais como a imunoglobulina do tipo $\mathrm{M}$ (IgM). Estas imunoglobulinas são produzidas constitutivamente e estão diretamente relacionadas com resposta humoral precoce contra invasão bacteriana $[65,66]$.

Em modelos experimentais de sepse (endotoxemia por LPS ou peritonite bacteriana por ligadura e punção cecal), a ausência de secreção de lgM promove maior taxa de mortalidade em camundongos imunodeficientes em linfócito B (Rag ${ }^{-}$ /') [67] ou deficientes em secreção de $\operatorname{lgM}(\operatorname{slg} M)$ [68]. A reposição de IgM leva a inversão do quadro de suscetibilidade nestes animais, diminuindo a taxa de mortalidade tanto aos estímulos inflamatórios ou infecciosos [67, 68].

Contudo, em nosso estudo com cultura de células B-1 não foi detectada a presença de imunoglobulina M. Este dado reforça a relevância da IL-10 como o mecanismo modulador da célula B-1 sobre a resposta do macrófago em resposta ao LPS.

O camundongo da linhagem Balb/Xid é um modelo natural de XLA, porém, menos severo $[46,47,49,69]$. Esta linhagem é deficiente em célula B-1 e desta forma pode ser utilizado para estudos in vitro e in vivo, possibilitando avaliar a participação da célula B-1 na endotoxemia por LPS. A análise fenotípica das 
células peritoneais destes camundongos por citometria de fluxo mostrou que a linhagem Balb/c possui $45 \%$ de célula B-1 enquanto que a linhagem Balb/Xid é desprovida desta célula (Figura 9). Os animais das linhagens Balb/Xid e Balb/c foram utilizados para pesquisa do perfil inflamatório das células peritoneais estimuladas com LPS e dos animais após injeção de LPS (i.p.).

O estudo de cultura das células peritoneais dos animais revelou que após o estímulo com LPS, a produção de TNF- $\alpha$, (Figura 10a), IL-6 (Figura 10b) e NO (Figura 10d) foram maiores em sobrenadante de cultura de células peritoneais de animais da linhagem Balb/Xid, quando comparamos com a linhagem Balb/c, enquanto que não foi observada diferença significativa na produção de IL-10 (Figura 10c).

Os mecanismos envolvidos na endotoxemia desencadeada pelo LPS em camundongos da linhagem Balb/Xid, ainda não estão esclarecidos. Nossos dados mostram que os animais da linhagem Balb/Xid estimulados com LPS apresentam maior taxa de mortalidade (Figura 11), perfil proinflamatório exacerbado em soro, pulmão e intestino enquanto que a produção de IL-10 permanece baixa tanto no soro quanto nos órgãos estudados (Figuras 12, 13 e 14) em relação aos animais da linhagem Balb/c. O desbalanço na produção dos mediadores inflamatórios após a inoculação de LPS pode estar diretamente relacionado à maior mortalidade observada em animais da linhagem Balb/Xid (Figura11).

As baixas concentrações de IL-10 podem estar relacionadas à ausência das células B-1 em peritônios de camundongos Balb/Xid, uma vez que essas células são grandes produtoras de IL-10 [70-73] 
O aumento de NO em modelos de endotoxemia por LPS está associado à patofisiologia da endotoxemia ou sepse associando-se a eventos tais como hipotensão, hiporresposividade a vaso constritor, dano às funções cardíacas e integridade vascular [74-76]. Em nosso estudo, as dosagens de nitrito no soro ocorreram após 1,5; 4 e 6 horas após a injeção de LPS em animais de ambas as linhagens estudadas. $\mathrm{O}$ aumento da produção de NO na endotoxemia é significativamente aumentada em modelo murino após 20 horas da injeção de LPS [77] e está relacionada ao aumento da enzima NO sintase induzível (iNOS ou NOSII) [78]. Desta forma, os períodos de tempo que foram determinados para o nosso estudo provavelmente foram precoces, não possibilitando a deteç̧ão do aumento da produção de NO (Figura 15).

Outros estudos mostraram que animais da linhagem Balb/Xid são resistentes à infecção por $T$. cruzi apresentando maior controle da parasitemia por exibirem altas concentrações de IFN- $\gamma$, IL-2, IL4 e menor produção de IL-10 no plasma, comparado com animais Balb/c. A ausência de células B-1 em Balb/Xid, provocou diminuição da produção de IL-10 e aumento dos níveis de IFN- $\gamma$, o qual está diretamente relacionado com a eliminação do parasita [71].

Hoerauf e colaboradores demonstraram que os camundongos da linhagem Balb/Xid também são resistentes a infecção por Leishmania major. Os animais apresentaram menores lesões, menor produção de anticorpos e altas concentrações de IFN- $\gamma[70]$.

Os animais da linhagem Balb/Xid também foram resistentes à infecção por Paracoccidioides brasiliensis, e esta resistência diminui à medida que são 
inoculadas células B-1 (WT) no peritônio destes camundongos. Este trabalho mostrou que após a repopulação com célula B-1, houve aumento da produção de IL-10, o que promoveu suscetibilidade à infecção por este fungo [55].

A sepse causa lesão de órgãos, a evolução para falência de múltiplos órgãos e o choque devido a uma resposta inflamatória exacerbada. Os resultados aqui apresentados em modelo de endotoxemia por LPS são contrastantes aos resultados obtidos em modelos de infecção por fungos ou parasitas. Enquanto a presença da célula B-1 promove suscetibilidade aos animais nos modelos de infecção por fungos e parasitas, em nosso modelo, a presença destas células confere proteção aos animais.

Estes resultados apontam que os linfócitos podem estar envolvidos também numa fase precoce do processo de eliminação do antígeno, mantendo o equilíbrio da produção de mediadores inflamatórios pelo hospedeiro. Resultados semelhantes foram encontrados por Kim e colaboradores [79] onde camundongos imunodeficientes em linfócitos T são mais suscetíveis aos efeitos da infecção por vírus (MHV-A59) exibindo perfil proinflamatório exacerbado.

Para verificar os efeitos da célula B-1 in vivo, realizamos experimentos de reconstituição de animais Balb/Xid com célula B-1. A reconstituição de células B-1 (provenientes de camundongos Balb/c) em peritônios de camundongos Balb/Xid mostrou que $1 \times 10^{6}$ céls./ml promoveu a proliferação de $2,5 \%$ de célula B-1 após 7 dias da inoculação (Figura 16). Esta concentração não promoveu aumento da taxa de sobrevida desses animais após exposição ao LPS (Figura 17). Este resultado pode estar relacionado com o fato de que a concentração de 2,5\% de célula B-1 
não seja suficiente para conferir proteção ao animal da linhagem Balb/Xid no modelo de endotoxemia por LPS

A participação da enzima tirosina quinase de Burton (Btk) na cascata inflamatória do LPS ainda é um assunto controverso na literatura. Schimidt e colaboradores [80] mostraram que a Btk é parcialmente envolvida na cascata de sinalização do LPS afirmando que há ativação parcial desta enzima diminuindo a atividade do fator de transcrição $\mathrm{NF} \kappa \beta$ de camundongos $\mathrm{Btk}^{\top}{ }^{-}$em relação ao $\mathrm{WT}$. O autor descreve ainda o aumento da produção de IL-6 e diminuição de IL-10 sem comentar sobre a imunodeficiência do animal. Entretanto, Perez de Diego e colaboradores [69] mostraram que a ausência da Btk não evitou o aumento da ativação da via das MAPK ERK1 e 2 Junk e p38 em células de sangue periférico de pacientes com XLA após 20 minutos de exposição ao LPS supondo assim que outra tirosina quinase deve compensar a falta da Btk em resposta ao LPS.

É importante realçar que o nosso objetivo foi estudar o papel da célula B-1 na endotoxemia e não a via da Btk. Desta forma os estudos com coculturas de macrófagos (RAW264.7) foram planejados fundamentalmente com células sem alteração da Btk. Contudo, o estudo das células peritoneais e o estudo in vivo ficaram limitados pela linhagem imunodeficiente disponível. 


\section{Conclusões}

A célula B-1 participa da resposta inflamatória ao LPS tanto in vitro quanto in vivo.

As células B-1 (Balb/c) em cultura, estimuladas com LPS apresentaram aumento significativo de IL-10 enquanto nenhuma diferença significativa na produção de TNF- $\alpha$, IL6 e nitrito foi encontrada quando comparamos com células B-1 sem estímulo. Estes dados demonstram que as células B-1 in vitro apresentaram perfil antiinflamatório.

A presença de células B-1 (Balb/c) em coculturas com macrófagos de linhagem (RAW 264.7) promoveu diminuição de mediadores proinflamatórios, como TNF- $\alpha$, IL-6, nitrito e aumento significativo de IL-10, quando comparamos com culturas de macrófagos isolados após estímulo com LPS. Este mecanismo é dependente da secreção de IL-10 pelas células B-1.

As produções de TNF- $\alpha$, IL-6 e nitrito foram menores em cultura de células peritoneais de camundongos Balb/c quando comparamos com Balb/Xid mostrando a presença das células B-1 promove diminuição de mediadores proinflamatórios após estímulo com LPS.

No estudo in vivo, nossos resultados mostram que animais da linhagem Balb/c apresentaram menor produção de mediadores proinflamatórios e maiores concentrações de IL-10 tanto em soro, pulmão e intestino após a injeção de LPS quando comparamos com animais Balb/Xid (imunodeficientes em célula B-1). Além disso, os animais da linhagem Balb/c exibiram maior taxa de sobrevida após a indução da endotoxemia por LPS. 
Nossos resultados in vivo revelaram que a célula B-1 participa da resposta inflamatória ao LPS, promovendo aumento da produção de IL-10 e conferindo maior taxa de sobrevida dos animais após a injeção de LPS. 


\section{Bibliografia}

1. Bone, R.C., et al., Definitions for sepsis and organ failure and guidelines for the use of innovative therapies in sepsis. The ACCP/SCCM Consensus Conference Committee. American College of Chest Physicians/Society of Critical Care Medicine. Chest, 1992. 101(6): p. 1644-55.

2. Silva, F., ed. Sepse. ed. Manole. 2007: São Paulo.

3. Angus, D.C., et al., Epidemiology of severe sepsis in the United States: analysis of incidence, outcome, and associated costs of care. Crit Care Med, 2001. 29(7): p. 1303-10.

4. Angus, D.C., et al., Epidemiology of severe sepsis in the United States: Analysis of incidence, outcome, and associated costs of care. Critical Care Medicine, 2001. 29(7): p. 1303-1310.

5. Bone, R.C., Sepsis syndrome. New insights into its pathogenesis and treatment. Infect Dis Clin North Am, 1991. 5(4): p. 793-805.

6. Cipolle, M.D., M.D. Pasquale, and F.B. Cerra, Secondary organ dysfunction. From clinical perspectives to molecular mediators. Crit Care Clin, 1993. 9(2): p. 261-98.

7. Vincent, J.L., Update on sepsis: pathophysiology and treatment. Acta Clin Belg, 2000. 55(2): p. 79-87.

8. Angus, D.C. and R.S. Wax, Epidemiology of sepsis: an update. Crit Care Med, 2001. 29(7 Suppl): p. S109-16. 
9. Pollack, M. and C.A. Ohl, Endotoxin-based molecular strategies for the prevention and treatment of gram-negative sepsis and septic shock. Curr Top Microbiol Immunol, 1996. 216: p. 275-97.

10. Delves, P.J. and I.M. Roitt, The immune system. Second of two parts. N Engl J Med, 2000. 343(2): p. 108-17.

11. Fontes B; Cabral, R.P., RS, Cirurgia do trauma. 2006: p. 521-536.

12. Jean-Baptiste, E., Cellular mechanisms in sepsis. J Intensive Care Med, 2007. 22(2): p. 63-72.

13. Matsuda, N. and Y. Hattori, Systemic inflammatory response syndrome (SIRS): molecular pathophysiology and gene therapy. J Pharmacol Sci, 2006. 101(3): p. 189-98.

14. Zhang, X. and D.C. Morrison, Lipopolysaccharide-induced selective priming effects on tumor necrosis factor alpha and nitric oxide production in mouse peritoneal macrophages. J Exp Med, 1993. 177(2): p. 511-6.

15. Sweet, M.J. and D.A. Hume, Endotoxin signal transduction in macrophages. J Leukoc Biol, 1996. 60(1): p. 8-26.

16. Nagy, L.E., Recent insights into the role of the innate immune system in the development of alcoholic liver disease. Exp Biol Med (Maywood), 2003. 228(8): p. 882-90.

17. Nomura, F., et al., Cutting edge: endotoxin tolerance in mouse peritoneal macrophages correlates with down-regulation of surface toll-like receptor 4 expression. J Immunol, 2000. 164(7): p. 3476-9.

18. Rietschel, E.T., et al., Bacterial endotoxin: molecular relationships of structure to activity and function. Faseb J, 1994. 8(2): p. 217-25. 
19. Benjamini, E.C., R; Sunshine, G, Imunologia. 2002.

20. Póvoa, P., Marcadores da sepsis. Revista de medicina intensiva, 2000. 9: p. 239-248.

21. Beutler, B. and A. Cerami, Cachectin: more than a tumor necrosis factor. N Engl J Med, 1987. 316(7): p. 379-85.

22. Bone, R.C., The pathogenesis of sepsis. Ann Intern Med, 1991. 115(6): p. 457-69.

23. Cerami, A., Inflammatory cytokines. Clin Immunol Immunopathol, 1992. 62(1 Pt 2): p. S3-10.

24. Philippart, F. and J.M. Cavaillon, Sepsis mediators. Curr Infect Dis Rep, 2007. 9(5): p. 358-65.

25. van der Poll, T. and H.P. Sauerwein, Tumour necrosis factor-alpha: its role in the metabolic response to sepsis. Clin Sci (Lond), 1993. 84(3): p. 247-56.

26. Blackwell, T.S. and J.W. Christman, Sepsis and cytokines: current status. $\mathrm{Br}$ J Anaesth, 1996. 77(1): p. 110-7.

27. Dinarello, C.A., Proinflammatory and anti-inflammatory cytokines as mediators in the pathogenesis of septic shock. Chest, 1997. 112(6 Suppl): p. 321S-329S.

28. Fisher, C.J., Jr., et al., Influence of an anti-tumor necrosis factor monoclonal antibody on cytokine levels in patients with sepsis. The CB0006 Sepsis Syndrome Study Group. Crit Care Med, 1993. 21(3): p. 318-27.

29. Keystone, E., J. Wherry, and P. Grint, IL-10 as a therapeutic strategy in the treatment of rheumatoid arthritis. Rheum Dis Clin North Am, 1998. 24(3): p. 629-39. 
30. Moncada, S., R.M. Palmer, and E.A. Higgs, Nitric oxide: physiology, pathophysiology, and pharmacology. Pharmacol Rev, 1991. 43(2): p. 10942.

31. Kubes, P., M. Suzuki, and D.N. Granger, Nitric oxide: an endogenous modulator of leukocyte adhesion. Proc Natl Acad Sci U S A, 1991. 88(11): p. $4651-5$.

32. Nava, E. and T.F. Luscher, Endothelium-derived vasoactive factors in hypertension: nitric oxide and endothelin. J Hypertens Suppl, 1995. 13(2): p. S39-48.

33. Vasta, $\vee$., et al., Identification of a specific transport system for L-arginine in human platelets. Biochem Biophys Res Commun, 1995. 206(3): p. 878-84.

34. Kilbourn, R.G., D.L. Traber, and C. Szabo, Nitric oxide and shock. Dis Mon, 1997. 43(5): p. 277-348.

35. Rackow, E.C. and M.E. Astiz, Pathophysiology and treatment of septic shock. Jama, 1991. 266(4): p. 548-54.

36. Thiemermann, C., Nitric oxide and septic shock. Gen Pharmacol, 1997. 29(2): p. 159-66.

37. Chevallier, N., et al., B-1-like cells exist in sheep. Characterization of their phenotype and behaviour. Immunology, 1998. 95(2): p. 178-84.

38. Hayakawa, K., R.R. Hardy, and L.A. Herzenberg, Peritoneal Ly-1 B cells: genetic control, autoantibody production, increased lambda light chain expression. Eur J Immunol, 1986. 16(4): p. 450-6.

39. Kantor, A.B. and L.A. Herzenberg, Origin of murine B cell lineages. Annu Rev Immunol, 1993. 11: p. 501-38. 
40. Almeida, S.R., et al., Mouse B-1 cell-derived mononuclear phagocyte, a novel cellular component of acute non-specific inflammatory exudate. Int Immunol, 2001. 13(9): p. 1193-201.

41. Popi, A.F., J.D. Lopes, and M. Mariano, Interleukin-10 secreted by B-1 cells modulates the phagocytic activity of murine macrophages in vitro. Immunology, 2004. 113(3): p. 348-54.

42. Hardy, R.R., et al., Demonstration of B-cell maturation in X-linked immunodeficient mice by simultaneous three-colour immunofluorescence. Nature, 1983. 306(5940): p. 270-2.

43. Hardy, R.R., et al., Murine B cell differentiation lineages. J Exp Med, 1984. 159(4): p. 1169-88.

44. Hayakawa, K., et al., Ly-1 B cells: functionally distinct lymphocytes that secrete IgM autoantibodies. Proc Natl Acad Sci U S A, 1984. 81(8): p. 24948.

45. Abbas, A.a.L., AH, Imunologia celular e molecular. 2005.

46. Vetrie, D., et al., The gene involved in X-linked agammaglobulinaemia is a member of the src family of protein-tyrosine kinases. Nature, 1993. 361(6409): p. 226-33.

47. Ganem, M.R., et al., [X-linked agammaglobulinemia in nine patients: review of the literature]. Rev Hosp Clin Fac Med Sao Paulo, 1997. 52(4): p. 187-94.

48. Winkelstein, J.A., et al., X-linked agammaglobulinemia: report on a United States registry of 201 patients. Medicine (Baltimore), 2006. 85(4): p. 193202. 
49. Rawlings, D.J., et al., Mutation of unique region of Bruton's tyrosine kinase in immunodeficient XID mice. Science, 1993. 261(5119): p. 358-61.

50. Jagtap, P., et al., Novel phenanthridinone inhibitors of poly (adenosine 5'diphosphate-ribose) synthetase: potent cytoprotective and antishock agents. Crit Care Med, 2002. 30(5): p. 1071-82.

51. Hotchkiss, R.S., et al., Sepsis-induced apoptosis causes progressive profound depletion of $B$ and CD4+ T lymphocytes in humans. J Immunol, 2001. 166(11): p. 6952-63.

52. Donze, H.H., et al., Human peritoneal B-1 cells and the influence of continuous ambulatory peritoneal dialysis on peritoneal and peripheral blood mononuclear cell (PBMC) composition and immunoglobulin levels. Clin Exp Immunol, 1997. 109(2): p. 356-61.

53. Duan, B. and L. Morel, Role of B-1a cells in autoimmunity. Autoimmun Rev, 2006. 5(6): p. 403-8.

54. Chishima, F., et al., Peritoneal and peripheral B-1-cell populations in patients with endometriosis. J Obstet Gynaecol Res, 2000. 26(2): p. 141-9.

55. Popi, A.F., et al., B-1 cells facilitate Paracoccidioides brasiliensis infection in mice via IL-10 secretion. Microbes Infect, 2008. 10(7): p. 817-24.

56. Vigna, A.F., et al., Granuloma formation in vitro requires B-1 cells and is modulated by Paracoccidioides brasiliensis gp43 antigen. Microbes Infect, 2006. 8(3): p. 589-97.

57. Fiorentino, D.F., et al., IL-10 inhibits cytokine production by activated macrophages. J Immunol, 1991. 147(11): p. 3815-22. 
58. Jacobs, F., et al., IL-10 up-regulates nitric oxide (NO) synthesis by lipopolysaccharide (LPS)-activated macrophages: improved control of Trypanosoma cruzi infection. Clin Exp Immunol, 1998. 113(1): p. 59-64.

59. Donnelly, R.P., H. Dickensheets, and D.S. Finbloom, The interleukin-10 signal transduction pathway and regulation of gene expression in mononuclear phagocytes. J Interferon Cytokine Res, 1999. 19(6): p. 563-73.

60. O'Farrell, A.M., et al., IL-10 inhibits macrophage activation and proliferation by distinct signaling mechanisms: evidence for Stat3-dependent and independent pathways. EMBO J, 1998. 17(4): p. 1006-18.

61. Lauw, F.N., et al., Proinflammatory effects of IL-10 during human endotoxemia. J Immunol, 2000. 165(5): p. 2783-9.

62. Gerard, C., et al., Interleukin 10 reduces the release of tumor necrosis factor and prevents lethality in experimental endotoxemia. J Exp Med, 1993. 177(2): p. 547-50.

63. Howard, M., et al., Interleukin 10 protects mice from lethal endotoxemia. J Exp Med, 1993. 177(4): p. 1205-8.

64. Dagvadorj, J., et al., Interleukin-10 inhibits tumor necrosis factor-alpha production in lipopolysaccharide-stimulated RAW 264.7 cells through reduced MyD88 expression. Innate Immun, 2008. 14(2): p. 109-15.

65. Martin, F. and J.F. Kearney, B-cell subsets and the mature preimmune repertoire. Marginal zone and B1 B cells as part of a "natural immune memory". Immunol Rev, 2000. 175: p. 70-9. 
66. Martin, F., A.M. Oliver, and J.F. Kearney, Marginal zone and B1 B cells unite in the early response against T-independent blood-borne particulate antigens. Immunity, 2001. 14(5): p. 617-29.

67. Reid, R.R., et al., Endotoxin shock in antibody-deficient mice: unraveling the role of natural antibody and complement in the clearance of lipopolysaccharide. J Immunol, 1997. 159(2): p. 970-5.

68. Boes, M., et al., A critical role of natural immunoglobulin $M$ in immediate defense against systemic bacterial infection. J Exp Med, 1998. 188(12): p. 2381-6.

69. Perez de Diego, R., et al., Bruton's tyrosine kinase is not essential for LPSinduced activation of human monocytes. J Allergy Clin Immunol, 2006. 117(6): p. 1462-9.

70. Hoerauf, A., et al., The Xid defect determines an improved clinical course of murine leishmaniasis in susceptible mice. Int Immunol, 1994. 6(8): p. 111724.

71. Minoprio, P., et al., Xid-associated resistance to experimental Chagas' disease is IFN-gamma dependent. J Immunol, 1993. 151(8): p. 4200-8.

72. O'Garra, A., et al., $L y-1 B(B-1)$ cells are the main source of $B$ cell-derived interleukin 10. Eur J Immunol, 1992. 22(3): p. 711-7.

73. O'Garra, A., et al., Production of cytokines by mouse B cells: B lymphomas and normal B cells produce interleukin 10. Int Immunol, 1990. 2(9): p. 82132. 
74. Hollenberg, S.M., R.E. Cunnion, and J. Zimmerberg, Nitric oxide synthase inhibition reverses arteriolar hyporesponsiveness to catecholamines in septic rats. Am J Physiol, 1993. 264(2 Pt 2): p. H660-3.

75. Julou-Schaeffer, G., et al., Loss of vascular responsiveness induced by endotoxin involves L-arginine pathway. Am J Physiol, 1990. 259(4 Pt 2): p. H1038-43.

76. Rietschel, E.T. and M. Schlaak, [After 100 years: bacterial endotoxins]. Immun Infekt, 1993. 21(2): p. 25.

77. Tracey, W.R., J. Tse, and G. Carter, Lipopolysaccharide-induced changes in plasma nitrite and nitrate concentrations in rats and mice: pharmacological evaluation of nitric oxide synthase inhibitors. J Pharmacol Exp Ther, 1995. 272(3): p. 1011-5.

78. Forstermann, U., et al., Isoforms of nitric oxide synthase: functions in the cardiovascular system. Eur Heart J, 1993. 14 Suppl I: p. 10-5.

79. Kim, K.D., et al., Adaptive immune cells temper initial innate responses. Nat Med, 2007. 13(10): p. 1248-52.

80. Schmidt, N.W., et al., Bruton's tyrosine kinase is required for TLR-induced IL-10 production. J Immunol, 2006. 177(10): p. 7203-10. 